\title{
Environmental and economic assessment of traffic-related air pollution using aggregate spatial information: A case study of Balneário Camboriú, Brazil
}

\begin{abstract}
Introduction

Transportation is one of the main determinants of atmospheric pollutant emissions in urban areas. This externality has direct environmental, economic and public health consequences. This paper aims at investigating the space-time patterns of traffic air pollution in Balneário Camboriú (Brazil) over projected temporal scenarios and at estimating the damage costs of traffic air pollution to support transport policy-making.
\end{abstract}

\section{Methods}

To estimate the emission rates of pollutants, emission factors and traffic data were jointly used, whereas the pollutant concentrations were estimated using the Gaussian plume dispersion model. To identify the affected areas as well as possible spatial heterogeneity patterns of air pollution within clustered areas, an exploratory spatial analysis was also conducted. To assess the economic impact of air pollution, damage costs were calculated for various pollutants.

Results

The modeling results show that oxides of nitrogen $\left(\mathrm{NO}_{2}\right)$ and oxides of sulphur $\left(\mathrm{SO}_{2}\right)$ pollutants exceed the limits of air quality legislation, especially at a distance up to 10 meters from the roads, while $60 \%$ and $71 \%$ of the intersections are found to yield pollutant concentrations above the thresholds, primarily during peak hours. The analysis also confirmed that homogeneous traffic zones with similar emission rates are spatially clustered exhibiting positive autocorrelation patterns. The results of the economic appraisal showed that the estimated costs of traffic-related emissions were $\$ 0.89, \$ 1.38$ and $\$ 1.43$ million/year, respectively, for the current, short-term and long-term scenarios.

\section{Conclusions}

This study serves as the first comprehensive analysis of traffic air pollution for the specific study region, providing implications and modeling tools that can be leveraged in public policies focusing on the elimination of the transportation-generated health burden. The developed analysis framework can also serve as a supporting tool for Public Agencies focusing on the high-level evaluation of traffic-related air pollution using limited and aggregate spatial and traffic data.

\section{Keywords}

Air pollution; Emission Factors; Exploratory spatial data analysis; Damage Costs; Traffic; Brazil

\section{Introduction}

Road transport and surface traffic constitute one of the major sources of environmental pollution in urban areas (Anastasopoulos et al., 2017; WHO, 2018; Shekarrizfard et al., 2018; 
Bigazzi and Rouleau, 2017). In Brazilian cities, the appraisal of air pollution levels has been little explored by health Agencies and Public Authorities, sometimes not receiving due importance. Among other social impacts, contaminants from the vehicular emissions can be quite burdensome for public health and local economies (Luo et al., 2018; Dey et al., 2018, Hyland and Donnelly, 2015).

Since the enactment of the Resolution of the Brazilian National Environment Council (CONAMA) 018/1986, the Program for the Control of Air Pollution by Motor Vehicles (PROCONVE) was established, with the objective of reducing the emission levels of pollutants by motor vehicles, especially in urban centers, among other provisions (Brazil, 1986). According to Andrade et al. (2017) Proconve was established in stages, as a program aiming to reduce traffic pollutants through increasingly restrictive standards. The emission limits for automotive vehicles were set with respect to the Otto cycle and diesel.

In 1989, the National Air Quality Control Program (PRONAR) was established by resolution 05/1989 (Brazil, 1989), which sets the national limits of emissions by source typology and priority pollutants. This resolution is complemented by Resolution 491/2018, by which air quality standards and classes have been determined (Brazil, 2018). This legal framework has set specific upper concentrations of pollutants, which, if exceeded, can affect the health, safety, and well-being of the population, as well as cause damage to the flora and fauna, materials and the environment, in general. The reference contaminants mentioned in the regulations are $\mathrm{CO}, \mathrm{SO}_{2}, \mathrm{NO}_{2}$, ozone, fume, and lead $(\mathrm{Pb})$.

Most of the studies available in the literature consider the municipal fleet as the main source of traffic-related pollutant emissions (MMA, 2011, 2013; CETESB, 2015). Although this consideration can provide a reasonable approximation of the municipal, state or national emissions, such an approach does not allow the identification of the emissions' distributional characteristics within the urban network. In addition, this approach does not account for actual traffic flows at a given moment. On the contrary, instantaneous forecasting models allow emissions to be resolved spatially, and, therefore have the potential to provide more accurate predictions of air pollution. In this context, over the last decades, there is a growing need to estimate and apply disaggregate models of air pollution using detailed measurements of vehicle volumes (Boulter et al., 2007).

In general, many developing countries, such as Brazil, have low quality and quantity of data available for both air quality and traffic monitoring. Traffic monitoring systems, which allow the development and maintenance of databases with counts of urban traffic flows, are available in a limited extent, and primarily, in large metropolitan areas (Pacheco et al., 2017). However, more accurate databases can support more complex analyses, such as mathematical modeling of air pollution; the latter can result in significant cost reduction, especially when compared to air quality monitoring (Lacava, 2003). In addition, mathematical modeling approaches may enable simulation of different scenarios under various conditions, estimation of concentrations in areas where monitoring is unfeasible, simulation of emergency actions, predictions of possible effects on natural and built environment, urban planning analyses as well as the development and evaluation of strategies for controlling air pollution (Derisio, 1992).

In this context, this study seeks to investigate the environmental and economic impacts of traffic air pollution in Balneário Camboriú, Brazil over projected scenarios as well as the possible damage costs arising from the traffic-related air pollution. The main contribution of the study is to understand the environmental and socioeconomic impacts of air pollution generated by urban vehicular traffic, considering a low-cost data acquisition to subsidize strategies for the improvement of urban air quality. 
To identify and appraise the geographic distribution of these impacts, maps of air pollution dispersion were developed, and a spatial analysis was conducted. Due to variations in the socio-demographic, traffic and built environment characteristics across the areas of the studied metropolitan area, the possible influence of spatial heterogeneity has been accounted for in the employed methodological framework.

The work was conceived in four distinct, yet interrelated stages (Figure 1): the first stage aims at estimating emission rates of pollutants in the municipalities using emission factors of pollutants and traffic flow data. The second stage refers to the estimation of the concentrations of these pollutants, which was performed by means of mathematical simulation using the Gaussian plume dispersion model. To investigate whether the actual concentrations match or exceed the legislation thresholds, the calculated concentrations are spatialized through thematic maps made using a Geographic Information System (GIS). The third stage constitutes a policy support appraisal, which is based on the identification of spatial dependence patterns of air pollution across the various homogeneous traffic zones of the studied metropolitan area. To that end, an exploratory spatial data analysis (ESDA) is conducted, with its findings assisting in shaping appropriate environmental countermeasures and harm-reduction policies. In the last stage, the financial cost of transport-related air pollution is estimated and evaluated using a wide variety of international case studies on damage costs, which allowed the calculation of the cost by each specific pollutant.

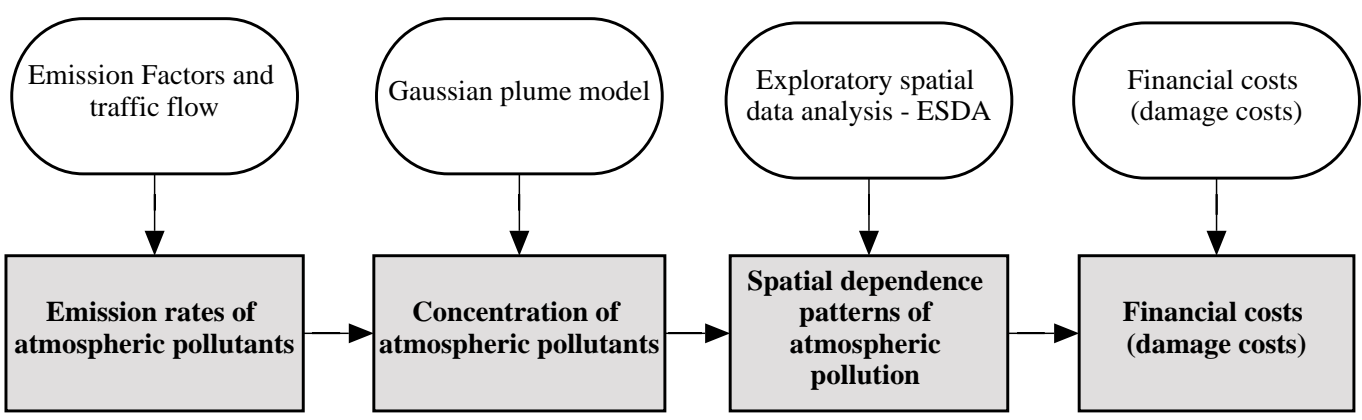

Figure 1. Four steps of the research carried out

\section{Background literature review}

\subsection{Pollution forecasting emission models using traffic data}

Air pollution dispersion modeling has been widely employed by practitioners and researchers, due to its capability to simulate concentrations of pollutants for different scenarios using traffic data, land use, and road system features as basic input. The merits of such a modeling approach are particularly evident when monitoring data of air quality are hardly available (Berkowicz et al., 2006). An alternate approach to estimating emissions from mobile sources is by correlating the traffic parameters referring to specific traffic situations - which are already known to the model user - and then, developing models based on emission factors.

Emission factors represent emitted quantities of specific pollutants per vehicle. These factors, as previously determined by specialized agencies, are generally expressed in mass emitted by distance traveled from the pollutant ( $\mathrm{g} / \mathrm{km} / \mathrm{vehicle}$ ) (USEPA, 1995). These factors are typically weighted considering road links and traffic conditions such as volume, traffic speed, and vehicle typology. According to Pan et al. (2016), the emission rate of a road link can be calculated as:

$$
E_{i}=R_{i} \sum_{j=1}^{n} F_{j} Q_{j}^{i}
$$


where $E_{i}$ is the emission rate of road link $i(\mathrm{~g} / \mathrm{h}), F_{j}$ is the emission factor of vehicle type $j$ $(\mathrm{g} / \mathrm{km})$, calculated on the basis of the link-based average traffic speed, $n$ represents the total number of vehicle types, $Q_{j}^{i}$ denotes the volume of vehicles per type $j$ in road link $i(\mathrm{veh} / \mathrm{h})$ and $R_{i}$ represents the length of the road link $i(\mathrm{~km})$.

Since 1972, USEPA (1995) has published a Compilation of Air Pollutant Emission Factors. The latter includes emissions factors and process information for more than 200 air pollution source categories. It should be noted that emission factors and emission inventories have long been fundamental tools for air quality management. In Brazil, the Environmental Authority developed a methodology based on emission factors, the application of which can shed more light on the relationships between traffic emissions and the resulting environmental concentrations. Upon their spatial calibration, such relationships can assist in the establishment of policies and actions that enable air quality standards to be respected (MMA, 2011).

Typically, manuals relate emission factors to different types of vehicles with substantial differences; for example, heavy vehicles have significant differences with passenger vehicles in terms of pollutant emissions (Jain et al., 2016; Bukowiecki et al. 2010). Furthermore, these factors are highly associated with specific traffic conditions. For application purposes, the model user typically defines a variable referring to the type of traffic situation to which an emission factor is applicable (i.g. free-flow, stop-and-go), instead of defining a specific speed variation (INFRAS, 2004).

Air pollution models constitute important tools for air quality management systems and can be employed by environmental authorities to support the development of effective strategies to reduce harmful atmospheric issues (USEPA, 2009). Paoli (2006) affirms that their use is more practical, reduces costs, and allows the simulation of scenarios as well as the determination of appropriate actions for tackling the patterns of air pollution in the short- and long-term future.

The study of Costabile and Allegrini (2008) has shown that the real-time integration of modeling results with actual measurements can act as a validation source and further enhance the real-time assessment of traffic-related air pollution. This makes the use of emission factors very appealing, regardless of their limitations (USEPA, 1995). However, there may remain gaps in the understanding of the relationship between road traffic and emission of pollutants (cause and effect mechanisms), especially in cases where traffic conditions may vary from location to location (Boulter et al., 2007). These gaps may arise from location-specific variations in terms of built-environment characteristics or land use, resulting, thus, in additional uncertainties with respect to the air pollution prediction.

Another group of studiesprovides emission factors using real conditions such as tunnel experiments (Martins et al., 2006; Sánchez-Ccoyllo, 2009; Pérez-Martínez et al., 2014; Alves et al., 2015). Smit et al. (2009) pointed out, the majority of air pollution models use emission factors that have been developed from vehicle emission tests in laboratories; the latter typically reflect controlled conditions of the vehicle use. It should be acknowledged that such a controlled environment may introduce considerable uncertainties in traffic emission models leading potentially to inaccurate predictions (e.g., underestimates of traffic emissions).

\subsection{Damage cost of emissions}

The damage caused by air pollution can be economically quantified by firstly assessing the environmental and public health impacts. Damage costs methods are used to estimate control and risk costs required to reduce emissions, either by preventing or mitigating them (VTPI, 2018). Such methods can also facilitate environmental decision making and support the identification of the most effective public policies (Shindell, 2015). Note that the use of damage 
cost methods serves as an alternative to the limited availability of primary monitoring data. Damage costs are expressed in monetary values per ton of pollutant, with their calculation being based on the emission reduction or increase and the associated values of benefit or harm, respectively (DEFRA, 2011).

Damage costs approximate the marginal costs caused by the additional emission (or reduction) of some mass of pollutants. The main goal of this approach is to support the assessment of environmental impacts and the choice of harm reduction alternatives and policies (DEFRA, 2011). In the UK, for example, these costs are used to evaluate national policies, programs, and projects, simplify appraisals on changes in pollutant emissions, and infer the non-internalized costs of pollution to society (UK-Government, 2015).

According to the New Zeeland's guidelines, the damage cost approach is more straightforward compared to the exposure modeling (NZTA, 2013). Specifically, for the latter, a thorough understanding of the influential factors (such as sources, terrain, meteorology, and others) is essential to reach a reliable prediction of pollutant concentrations (NZTA, 2013). In the context of the program "Clean Air for Europe", monetized damage costs per ton of pollutant $\left(\mathrm{PM}_{2.5}, \mathrm{SO}_{2}, \mathrm{NO}_{2}, \mathrm{NH}_{3}\right.$, and VOC) have been estimated for each European Union country taking care, at the same time, for possible variations across the sites of emission. For example, for $\mathrm{NO}_{2}$, an average damage cost of $€ 4,107$ was calculated, with values ranging from $€ 530-9,600$, whereas for $\mathrm{SO}_{2}$, an average damage cost of $€ 5,368$ was identified, with values ranging from $€$ 1,400-13,000 (AEA-TE, 2015). It is worth mentioning that specific aspects of the air pollution's effect, such as impacts on ecosystems and cultural heritage, were not included in this calculation of the damage cost.

Table 1 provides examples of damage costs that were used to value environmental externalities and assess national policies, programs, and projects of different countries. The values provided are presented in the country's currency as well as in equivalent US dollar (\$) amounts per ton of emission change.

Table 1. Average damages per ton of emission. Source: UK-DEFRA, 2015, NZTA (2013), Austroads, 2012, AEA-TE (2005).

\begin{tabular}{|c|c|c|c|c|}
\hline \multirow{2}{*}{ Location } & \multirow{2}{*}{ Pollutant } & \multirow{2}{*}{ Central value } & \multicolumn{2}{|c|}{ Central sensitivities } \\
\hline & & & Low & High \\
\hline \multirow{4}{*}{$\begin{array}{l}\text { United } \\
\text { Kingdom }\end{array}$} & $\mathrm{NO}_{2}$ (Transport average) & $£ 21,044(\$ 27,329.9)$ & $£ 8,417$ & $£ 33,670$ \\
\hline & PM (Transport urban medium) & $£ 66,264(\$ 86,057.1)$ & $£ 51,881$ & $£ 75,300$ \\
\hline & $\mathrm{SO}_{2}$ & $£ 1,956(\$ 2,540.3)$ & $£ 1,581$ & $£ 2,224$ \\
\hline & $\mathrm{NH}_{3}$ & $£ 2,363(\$ 3,068.8)$ & $£ 1,843$ & $£ 2,685$ \\
\hline Location & Pollutant & Costs in NZD/ton & \multicolumn{2}{|c|}{ Costs in US\$/ton } \\
\hline \multirow{4}{*}{$\begin{array}{l}\text { New } \\
\text { Zealand }\end{array}$} & $\mathrm{PM}_{10}$ & $460,012.00$ & \multicolumn{2}{|c|}{$308,208.0$} \\
\hline & $\mathrm{NO}_{2}$ & $16,347.00$ & \multicolumn{2}{|c|}{$10,952.5$} \\
\hline & $\mathrm{CO}$ & 4.13 & \multicolumn{2}{|c|}{2.78} \\
\hline & $\mathrm{HC}$ & $1,310.00$ & \multicolumn{2}{|c|}{877.7} \\
\hline Location & Pollutant & Costs in AU\$/ton & \multicolumn{2}{|c|}{ Costs in US\$ /ton } \\
\hline \multirow{3}{*}{ Australia } & $\mathrm{CO}$ & 3.3 & \multicolumn{2}{|c|}{2.38} \\
\hline & $\mathrm{NO}_{2}$ & $2,089.2$ & \multicolumn{2}{|c|}{$1,504.2$} \\
\hline & PM10 & $332,505.9$ & \multicolumn{2}{|c|}{ 239,418.6 } \\
\hline Location & Pollutant & Costs in $€ /$ ton & \multicolumn{2}{|c|}{ Costs in U\$S/ton } \\
\hline \multirow{3}{*}{ Europe } & $\mathrm{NO}_{2}$ & 4,400 & \multicolumn{2}{|c|}{$5,016.0$} \\
\hline & $\mathrm{PM}_{2.5}$ & 26,000 & \multicolumn{2}{|c|}{29,600} \\
\hline & $\mathrm{SO}_{2}$ & 5,600 & \multicolumn{2}{|c|}{$6,384.0$} \\
\hline
\end{tabular}




\section{Data collection and preliminary analysis}

The available data that were used in this study refer to samples of traffic volumes collected at road intersections in the city of Balneário Camboriú, which is located in the State of Santa Catarina in southern Brazil. The population of the city is about 150,000, with the vast majority of inhabitants being located in highly urbanized areas. The city constitutes a regional economic hub as well as an important relevant tourist destination of the country (IBGE, 2016), mainly due to its extensive coastline. The city currently faces severe issues related to urban mobility, such as traffic congestion, transit inefficiencies, air and noise pollution, being, thus, one of the most significant urban mobility challenges in the State.

Although Balneário Camboriú is a medium-size city, its urban mobility problems are similar to those encountered by large metropolitan areas of the country. According to 2010 census (IBGE, 2010), there are 151 municipalities with a population between 100-200k inhabitants, and 95 municipalities with a population between $200-500 \mathrm{k}$ inhabitants, representing - in total - a population of more than 64 million people (33.7\% of the country's population). In this context, the medium-sized cities may constitute a significant generator of traffic-related emissions; hence, the reduction of socio-economic and environmental externalities arising from urban mobility patterns in such settings is of strategic importance, region-wise and country-wise.

Figure 2 shows the location of the 50 intersections that were included in our analysis. The data collection was conducted only on weekdays (Monday to Thursday) between March 2017 and November 2017. The specific period was selected to avoid bias possibly stemming from seasonal effects and summer tourism. Traffic counts were conducted at intersections through an iterative process ${ }^{1}$. Since the City Council has not employed any traffic monitoring system, the collection of citywide traffic data was a challenging task. Interestingly, we combined traffic data available from studies and reports of the City Council (Studies of Impacts on Neighborhood - Estudos de Impacto de Vizinhança) and on-site counts using video recordings from traffic cameras positioned at intersections. It should be noted that our sample primarily consists of on-site traffic counts. On a daily basis, the volumes were measured from 7.00 through 9.00 in the morning slot, and from 17.00 through 19.00 in the evening slot. These time slots were strategically selected to capture the prevailing traffic patterns during peak hours.

\footnotetext{
${ }^{1}$ At least three traffic counts were conducted at the same intersection.
} 


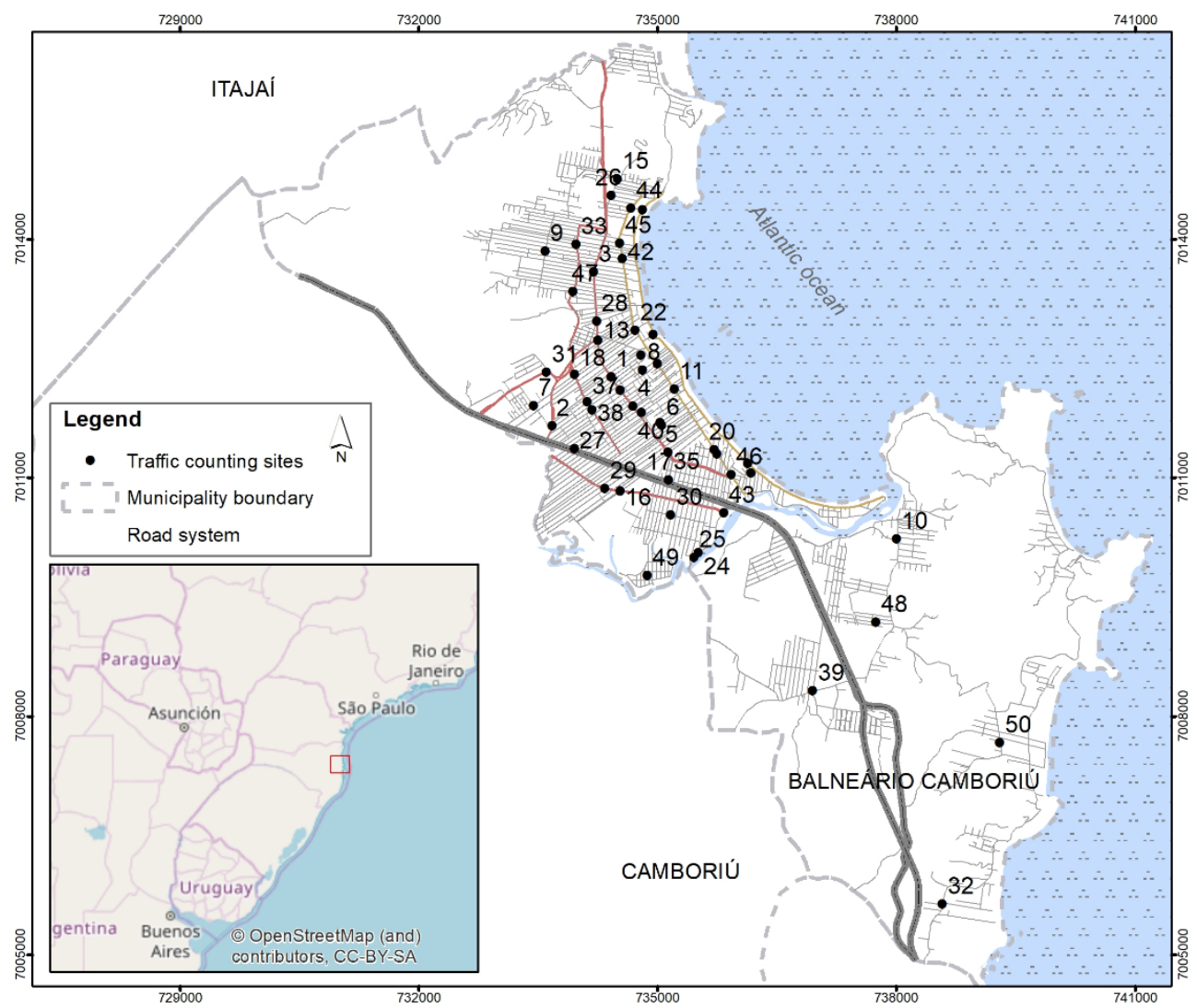

Figure 2. Location of traffic samples intersections.

To verify daily and seasonal changes in traffic flow, radar traffic data were drawn from six monitoring points. The radar data were made available by the Balneário Camboriú City Council (PMBC, 2017). Note that detailed time series of historical traffic data were not available by the local reporting system. In line with previous studies (Capraz et al., 2016; Fang et al., 2017), to identify statistical variations of traffic flow patterns over time, multiple F-tests were conducted. According to the formulation of the specific statistical test, the test statistic is assumed to follow the F-distribution; for further details on the statistical assumptions underpinning the F-test, see also Washington et al. (2011). The statistical analysis of the radar data showed that, although there is a significant variation of traffic volumes between season and off-season months - possibly due to higher tourist flows - the traffic volumes exhibit overall consistent patterns. Specifically, statistically significant differences (with greater than 99\% level of confidence, since the average p-value was equal to 0.009 ) were identified between the summer season months (January-March) and the off-season months (August-November). On a weekly basis, Fridays are found to be associated with statistically different traffic patterns relative to the other weekdays (with greater than $95 \%$ level of confidence since the average pvalue was equal to 0.004). Taking into account the aforementioned findings, the traffic characteristics of weekdays during off-season months are considered as a baseline for the interpretation of the outcomes of this study. 
In order to estimate the effects of air pollution throughout the city, it was necessary to extrapolate the traffic flows to the entire urban network. For the extrapolation, two fundamental criteria were used: (i) road hierarchy; and (ii) homogeneous traffic zones (HTZ), as conceived by Tischer (2017). Homogeneous Traffic Zones are defined using socioeconomic criteria and represent locations classified with respect to their potential in generating and attracting trips. Following an ordinal scale, High-level zones (e.g., Z5) are overall associated with high demographic density, income level, and economic potential. On the contrary, low-level zones (Z1) are associated with low demographic density, income level, and economic potential.

The hourly vehicle flow was separated in peak hour and average daytime hour, composing, thus, two matrices. Table 3 provides the split of peak hour traffic and average daytime hour traffic per traffic zone and road hierarchy type. Note that the values arranged in the matrix were obtained by the average of the hourly vehicle flow, which was available from the traffic count samples. Table 3 shows that the higher the traffic zone rank (traffic zones range from Z1 to Z5) and the road hierarchy (ranging from Local roads to Arterial roads - see also the "Material and Methods" section for further information), the higher is the traffic generated by that zone.

Table 2. Estimated vehicle flows per lane for peak and average daytime hours in the city of Balneário Camboriú, Brazil.

\begin{tabular}{|c|c|c|c|c|c|c|c|c|c|c|}
\hline \multirow[b]{3}{*}{$\begin{array}{l}\text { Hierarchy } \\
\text { Traffic Zone }\end{array}$} & \multicolumn{10}{|c|}{ Vehicle per hour per lane per road hierarchy and HTZ } \\
\hline & \multicolumn{5}{|c|}{ Peak time } & \multicolumn{5}{|c|}{\begin{tabular}{|c|} 
Average daytime hour \\
\end{tabular}} \\
\hline & $\begin{array}{c}\text { Arterial } \\
1 \\
\end{array}$ & $\begin{array}{c}\text { Arterial } \\
2 \\
\end{array}$ & $\begin{array}{c}\text { Collector } \\
1 \\
\end{array}$ & $\begin{array}{c}\text { Collector } \\
2 \\
\end{array}$ & Local & $\begin{array}{c}\text { Arterial } \\
1 \\
\end{array}$ & $\begin{array}{c}\text { Arterial } \\
2 \\
\end{array}$ & $\begin{array}{c}\text { Collector } \\
1 \\
\end{array}$ & $\begin{array}{c}\text { Collector } \\
2 \\
\end{array}$ & Local \\
\hline $\mathrm{Z1}$ & 710 & 733 & 575 & 297 & 18 & 547 & 375 & 462 & 180 & 10 \\
\hline $\mathbf{Z 2}$ & 837 & 773 & 611 & 463 & 144 & 621 & 429 & 458 & 343 & 95 \\
\hline $\mathbf{Z 3}$ & 931 & 791 & 704 & 438 & 100 & 586 & 477 & 520 & 275 & 82 \\
\hline $\mathbf{Z 4}$ & 795 & 756 & 486 & 444 & 165 & 644 & 550 & 450 & 334 & 135 \\
\hline $\mathbf{Z 5}$ & 1,042 & 799 & 775 & 446 & 146 & 734 & 585 & 514 & 341 & 98 \\
\hline
\end{tabular}

Regarding the composition of the observed traffic, Table 4 shows that there is a predominance of passenger cars representing more than $68 \%$ of the traffic flow. Motorcycles represent about $19 \%$ of the traffic flow, whereas heavy vehicles (trucks and buses) represent approximately 2.9 and 3.5\% of the flow (corresponding to daytime average and peak hour, respectively).

Table 3. Average composition of the traffic in the Balneário Camboriú, Brazil.

\begin{tabular}{lccccc}
\hline Reference Hour & Cars & Motorcycles & Buses & Trucks & Bicycles \\
\hline Peak & $69.2 \%$ & $19.3 \%$ & $1.5 \%$ & $1.4 \%$ & $8.6 \%$ \\
Daytime Average & $68.0 \%$ & $19.0 \%$ & $1.7 \%$ & $1.8 \%$ & $9.4 \%$ \\
\hline
\end{tabular}

To compare future trends based on the demographic dynamics of the municipality, the emissions of pollutants were also considered over a 20 -year and a 40 -year time horizon. For the investigation of such future trends, we did not consider the implementation of measures that could change abruptly the operating conditions of the transportation network. To enable a projection over time, an exponential trend equation of growth rates relating to the vehicle fleet was established, using data from 2002 through 2018 (Detran/SC, 2018). The exponential equation (trend line) allowed the projection of the growth rate for the requested time horizons, as shown in Figure 3, the exponential form provided the best adjusted values against other curve forms (linear, logarithm, power), which were also investigated and found to project the rates at very high levels. For further details on statistical inference using fitted trend lines, see also Washington et al. (2011). Despite the anticipated increase of the vehicle fleet over the next decades, it is evident that the growth rate exhibits a substantially declining trend. 


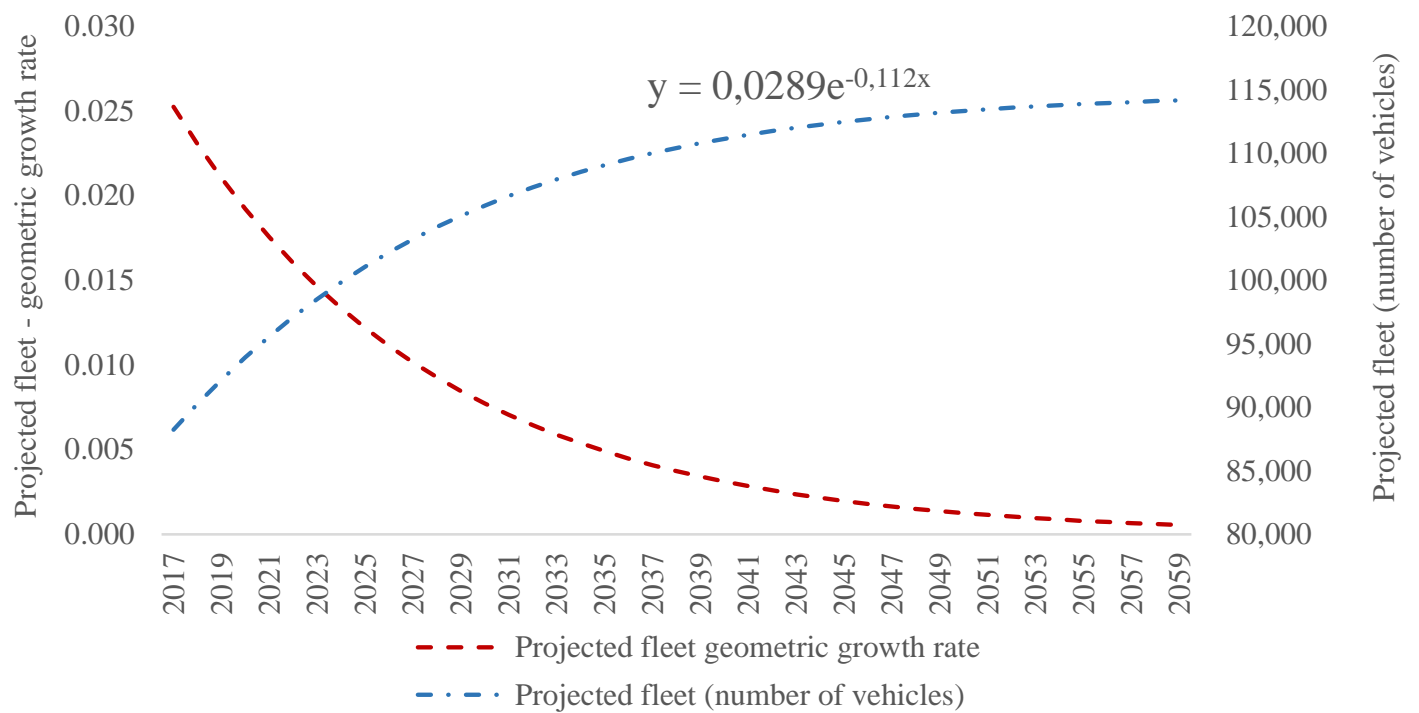

293 Figure 3. Projected geometric growth rate of the vehicle fleet in Balneário Camboriú. Source:

294 Registered vehicle data Detran/SC (2018)

295

296

297

298

299

300

\section{Material and Methods}

In order to evaluate the impact of pollution caused by mobile sources in the municipality, highly disparate input data (traffic data, road characteristics, fleet data, and emission factors) were collated in one comprehensive dataset. The latter allows the estimation of the emission rates, which, in turn, ate transformed into emission concentrations. Subsequently, such values enable the comparison with the legislative environmental thresholds.

Using the Geographic Information System (GIS) environment, a geographic dispersion analysis is conducted. In the context of this analysis, the pollutant concentrations are counterimposed against the legislation thresholds. Furthermore, the possibility of spatial autocorrelation between the studied intersections is also investigated. Besides the environmental and health implications, the outcomes of the developed methodological framework include an economic appraisal focusing on damage costs of air pollution. Figure 4 provides a comprehensive flowchart with all the stages, steps and outcomes of the methodological framework.

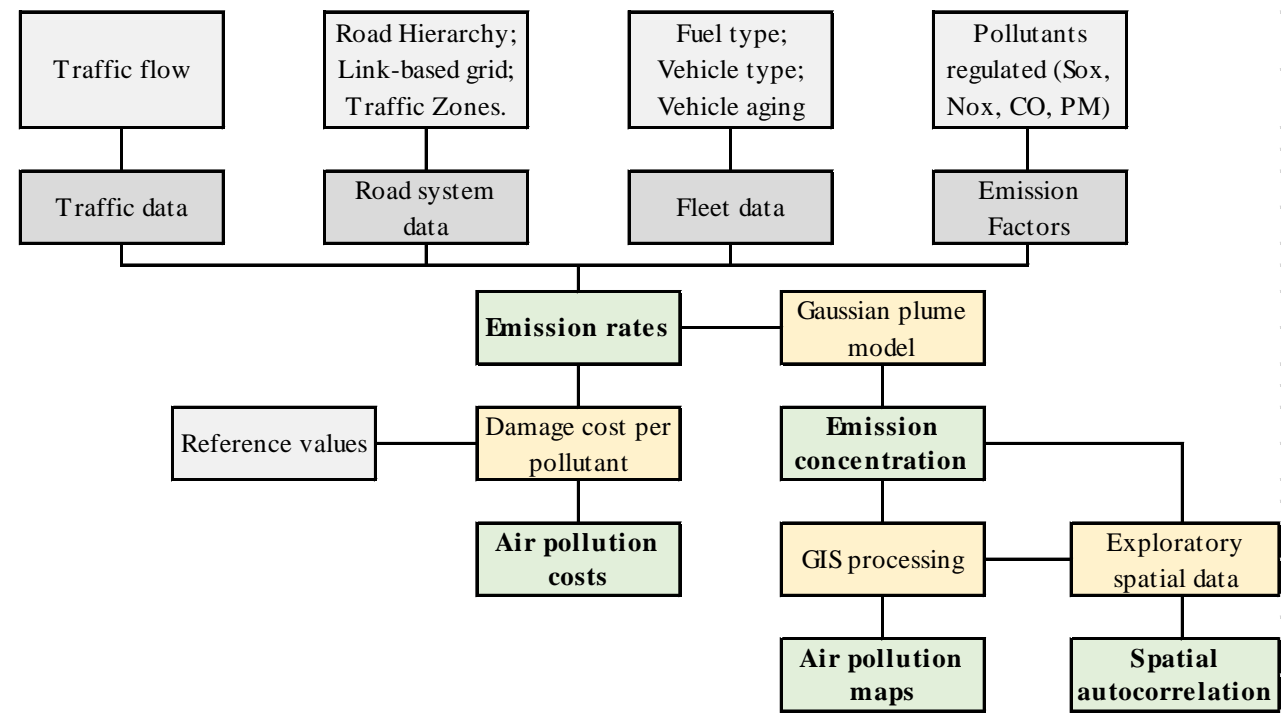

Figure 4. Comprehensive synthesis of the analysis steps. 


\subsection{Fuel type and average age of vehicles}

Fuel is an important factor in measuring pollutants rates. According to Gualtieri and Tartaglia (1998) and Londono et al. (2011), it is typically assumed that light vehicles use predominantly gasoline whereas the heavy vehicles use diesel. ${ }^{2}$

Regarding the age of the vehicles, we adopt assumptions about the municipal fleet age, which were based on data from the State Department of Traffic (Detran, 2017). Specifically, the analysis of the latter data verified that the average service life of the city's vehicles is approximately 8 years, with 5 years being the most frequently observed vehicle age (mode of the vehicle age). Figure 5 provides a graph with the historical evolution of the fleet size of Balneário Camboriú over the last 90 years. Following the considerations of the CETESB manuals (CETESB, 2009; CETESB, 2017), the vehicle age was drawn from Figure 5 and used for weighting the emission factors of pollutants.

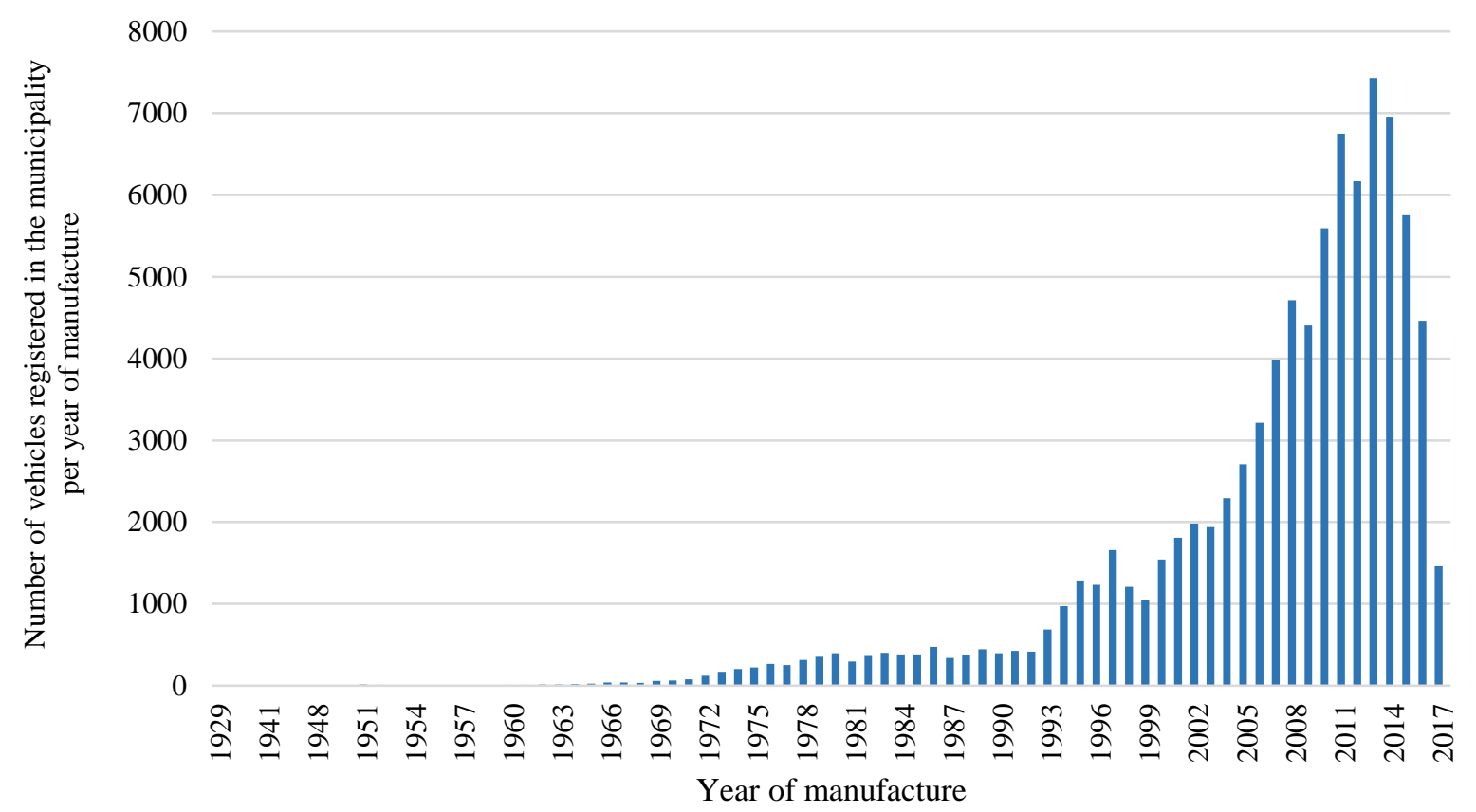

Figure 5. Number of vehicles registered in the municipality of Balneário Camboriú, Brazil per year of manufacture. Source: Detran/SC, 2017.

\subsection{Determination of links}

Vehicle emission inventories in Brazil estimate the emission of pollutants for vehicle trips as a function of the registered fleet and the average distance traveled by the specific fleet (as in the MMA, 2011). Herein, it is not possible to adopt this fleet-based method for traffic

\footnotetext{
${ }^{2}$ It should be noted that a large part of the light vehicles fleet in Brazil consists of flex vehicles, which can run on gasoline and ethanol. However, in the southern region of Brazil, this fuel has been little used, as the operation cost of these vehicle is higher compared to gasoline-based vehicles. The use of such vehicles is much more evident in the Southeast and Northeast regions, which constitute producing regions of ethanol. Interestingly, according to the association of merchants of fuel (Sindópolis) (DC, 2018), the gas stations in the case study region are stopping selling this fuel due to low demand. In addition, data from the National Agency of Petroleum, Natural Gas and Biofuels indicate that the consumption of ethanol in the municipality of Balneário Camboriú represents $3.25 \%$ of the total fuel consumption. That is $2,493.6 \mathrm{~m}^{3}$ of ethanol, as opposed to $74,164.1 \mathrm{~m}^{3}$ of gasoline, in the year 2016 (ANP, 2019). Hence, due to the low demand in the case study area, and due to limitations related to the estimation of the shares of these vehicles in the traffic fleet and the estimation of the corresponding fuel consumption, the specific group was not considered.
} 
flow data, since the same vehicle is likely to cross multiple, adjacent intersections; possible over-counting of the flows in the intersections may introduce significant bias in the analysis. To account for the fact that the circulation of vehicles at one point can influence the flows at adjacent points, linked-based techniques are employed. In inventory emissions appraisals, linkbased studies are considered advantageous because of providing spatial perspectives to the analysis (Yao and Song, 2013, Pan, 2016, Borge et al., 2012, Zhang et al., 2016, Gualtieri and Tartaglia, 1998; and Gois et al., 2007).

GIS procedures were used to obtain the extensions of the road links. Following the approach of Zhang et al. (2016), the roads were classified in 5 categories on the basis of their hierarchy: arterial 1 and 2, collector 1 and 2 and local roads. Arterials serve major areas and provide a high degree of mobility. Minor arterials serve geographic areas that are smaller compared to those served by the major arterials. Collectors gather traffic from local roads and funnel them to the arterial network. Local roads are not designated for long-distance trips, apart from providing access at the origin or destination of the trip. Table 5 provides the number of links as well as the average link length per each road hierarchy type.

\section{Table 4. Average link extension of the road system per road hierarchy}

\begin{tabular}{lccc}
\hline Road hierarchy & Links & L (m) & Average link extension (km) \\
\hline Arterial 1 - A1 & 173 & 11,794 & 0.068 \\
Arterial 2 - A2 & 524 & 35,288 & 0.067 \\
Collector 1 - C1 & 419 & 47,500 & 0.113 \\
Collector 2 - C2 & 164 & 17,388 & 0.106 \\
Local - L & 1,823 & 239,820 & 0.132 \\
Total & $\mathbf{3 , 1 0 3}$ & $\mathbf{3 5 1 , 7 9 0}$ & $\mathbf{0 . 0 9 7}$ \\
\hline
\end{tabular}

\subsection{Pollutants and Emission Factors}

Brazilian air quality legislation (Conama 491/2018) provides a set of indicators that need to be monitored in order to maintain environmental and public health. Out of the pollutants listed by that resolution, $\mathrm{CO}, \mathrm{NO}_{2}$, Particulate Matter, and $\mathrm{SO}_{2}$ have been previously studied in-depth by various environmental authorities (MMA, 2014, Ibama, 2014, CETESB, 2017) using the emission factor-based approach. The emission factors used in this study were drawn from CETESB (2017). The emission factors that were used in this study are presented in Table 6 . These factors were weighted according to the year of vehicle manufacture to $\mathrm{CO}, \mathrm{NO}_{2}$ and PM contaminants. $\mathrm{SO}_{2}$ factor was used from CETESB (2009), due to the absence of yearly reference value in the recent reports.

Table 5. Employed emission factors for air pollutants. Source: CETESB, 2017, CETESB (2009)

\begin{tabular}{cc|cccc}
\hline \multicolumn{2}{c|}{ Vehicle data } & \multicolumn{4}{c}{ Emission factors (g/km) } \\
\hline Type & Fuel & $\mathbf{C O}^{3}$ & $\mathbf{N O}_{2}{ }^{3}$ & $\mathbf{P M}^{3}$ & $\mathbf{S O}_{2}{ }^{\mathbf{3}}$ \\
\hline Light & Gasoline & $2.71-$ & 0.02 & 0.0012 & 0.07 \\
Motorcycles & Gasoline & 1.28 & 0.09 & 0.0042 & 0.02 \\
Heavy & Diesel & 0.82 & 4.68 & 0.20 & 0.13 \\
\hline
\end{tabular}

\subsection{Emission and concentration of pollutants}

The emission - typically expressed as a ratio of mass per time - is a function of the type and volume of vehicles as well as of the emission factors, which are intrinsic to each type of

\footnotetext{
${ }^{3}$ Emission factor weighted accordingly to the year of the vehicle manufacture.

${ }^{4}$ CETESB (2009).
} 
pollutant. However, air quality measures are typically expressed in concentration units (mass per volume). Consequently, to estimate the dispersion of the contaminant through the air as well as its concentration at the receptor, the application of a mathematical model is necessary. In this study, the Gaussian plume dispersion model is employed. This modeling approach attempts to describe and solve physical processes within a distinct mathematical and numerical framework, although it employs simplified flows over flat terrain (Tripathi et al., 2018). For model implementation, the following default values were used: $h=0.4 \mathrm{~m}$; diameter of release $=0.05 \mathrm{~m} ; u=1 \mathrm{~m} / \mathrm{s}$; ambient temperature $=25^{\circ} \mathrm{C}$; Atmospheric condition category $=$ slight unstable. Note that the default climate values for the Gaussian plume dispersion model were to based on the study of Araujo et al. (2009). Although the model considers general characteristics of atmospheric stability class, specific climatic characteristics such as ocean breeze, winds, and rainfall were not included in the model specification; the latter should be taken into account when interpreting the results.

For the implementation of the Gaussian plume dispersion model, the tool developed by NCSEC (http://www.ncsec.org/) was used, where the Gaussian routine method is incorporated in an Excel-based application. The rates and concentrations (in $\mathrm{kg} / \mathrm{h}$ and $\mu \mathrm{g} / \mathrm{m}^{3}$, respectively), were estimated per each intersection of the study area. The consideration of different homogeneous zones and hierarchy levels (as presented in Table 3) allowed us to extrapolate the concentration values for the entire road network of the municipality. After the calculation of the concentrations, a GIS analysis was then undertaken to map the spatial distribution of concentrations per each contaminant considered in the study. The latter helped obtain isolines of concentrations and perform, then, linear interpolation for the emitting points (intersections). The concentrations values were, in turn, aggregated in nominal classes using the legal concentration thresholds for each pollutant type as a reference basis.

\subsection{Air Pollution spatial analysis}

Initially, all the intersections of the city roads were determined and classified with respect to the traffic zone and the road hierarchy associated with each of them, following the approach of Tischer (2017). That was accomplished in a Geographic Information System (GIS) environment. Using the homogeneous traffic zones established within the studied municipality as well as the measured traffic flows, the methodology aims at identifying intersection-specific factors that will enable the appraisal of the air pollution level at a specific location. The calculations of the concentration of the contaminants were combined with the attribute worksheet of the intersections in the GIS environment. This allowed the development of thematic maps by each type of pollutant. The maps were classified by reference to the threshold concentrations of the Brazilian air quality legislation Conama 491/2018 (Brazil, 2018).

The previously mentioned legislation establishes air quality standards based on the effects on health, safety, and well-being of the population and the environment. To that end, it determines primary and secondary quality standards. In this study, we considered a day-based scale of concentrations for the first stage of implementation. The upper concentrations are specified as: $\mathrm{SO}_{2}: 125 \mu \mathrm{g} / \mathrm{m}^{3}$ (24-h), $\mathrm{NO}_{2}: 260 \mu \mathrm{g} / \mathrm{m}^{3}$ (1-h), particulate matter: $240 \mu \mathrm{g} / \mathrm{m}^{3}(24-$ h), and CO: 9ppm (converted to 9,000 $\mathrm{\mu g} / \mathrm{m}^{3}$ ) (8-h) (Brazil, 2018).

The development of thematic maps of dispersion of pollutants requires the use of generalized functions, due to the need for extrapolating the pollutants concentration data, which were calculated for the intersections, to the entire urban area. For this purpose, the Natural Neighbor interpolation algorithm was employed. This approach identifies groups geographically close to the interpolated points and creates values by applying weights 
proportional to the distance between them (Sibson, 1981; Arcgis, 2018). In this context, maps were developed for the four pollutants by considering the peak and average daytime hours of the vehicle flows.

Besides the geographic analysis of pollutants dispersion, an Exploratory Spatial Data Analysis (ESDA) was also conducted to identify clusters with similar air pollution patterns in the municipality. This type of analysis can assist in the formation of land use and transportation policies and the preliminary identification of spatial dependence of transportation-related air pollution that may warrant further investigation.

\subsubsection{Exploratory Spatial Data Analysis (ESDA)}

Due to its dispersion, air pollution can be expressed in spatial terms. The spatial variations of the traffic or built environment characteristics that determine the air pollution levels may introduce spatial heterogeneity in the distribution of air pollution across the city districts (Lin and Ge, 2006; Sun et al., 2017). Thus, the possible presence of geographically associated clusters or spatial differentiations between specific points should be taken in account to evaluate the validity of air pollution predictions and to possibly identify social gradients that may have an influence on pollutants’ exposures (Jerrett et al., 2005, Briggs et al., 2000).

One of the fundamental hypotheses of this study is the spatial relationship between air pollution and traffic zones. According to Anastasopoulos et al. (2010), spatial dependence constitutes a significant spatial effect and can be defined as the co-variation of properties inserted in a spatial system. This relationship is also called spatial autocorrelation and can be used to identify similar patterns that can be joined in clusters. Specifically, autocorrelation considers the sample points, focusing on their locations and the values associated with them (Ord and Getis, 1995). Spatial autocorrelation allows hypotheses to be tested to evaluate the relationship between variables in space resulting, thus, in a better understanding of the effects among each other within the same geographical context (Getis, 2007). The clustering of similar values of a variable in adjacent spatial units indicates the presence of positive spatial autocorrelation; when geographic areas tend to be surrounded by neighbors with very different values, there is strong evidence for the presence of negative spatial autocorrelation (Khomiakova, 2008). The study of Lorant et al. (2001) has shown that the use of spatial autocorrelation in regression models may affect the relationship between pollutant emissions and traffic zones. To that end, the possibility of autocorrelation likely underpinning the spatial structure of the data should be investigated in order not to lead to erroneous conclusions.

In this study, the geographical connections between the traffic zones were specified on the basis of the contiguity indicator, which assumes that interactions are present only if two zones share a common border (Anselin, 2018), considering up to 10 neighboring zones. To explore whether spatial dependence patterns of air pollution are statistically evident across the traffic zones, the Moran's I test was conducted. The test statistic can be defined as (Anastasopoulos et al., 2010; Tang et al., 2013; Zou et al., 2014):

$$
I=\left(\frac{n}{E}\right) \cdot\left(\frac{z^{\prime} W z}{z^{\prime} z}\right)
$$

Where $z$ is a vector containing $n$ observations measured in deviation from the mean, $W$ is a spatial weights matrix with $n \times n$ elements representing the spatial topology of the system, and $E$ denotes the sum of elements of the $W$. Moran's I local can provide insights regarding the degree of spatial autocorrelation at each specific location; for its calculation, 999 permutations were used (see also Anastasopoulos et al., 2010; Anselin, 2018).

To identify possible spatial autocorrelation patterns, the exploratory analysis of spatial data was performed through the software Geoda (Anselin, 1996). Along with Moran’s I test, 

485

\begin{tabular}{cccccc}
\hline Pollutant & Moran's I & Mean & Sd & z-value & Pseudo p-value \\
\hline $\mathrm{SO}_{2}$ & 0.264 & -0.0104 & 0.0647 & 4.239 & 0.001 \\
$\mathrm{CO}$ & 0.103 & -0.0037 & 0.0620 & 1.732 & 0.043 \\
Particulate Matter & 0.238 & -0.0113 & 0.0645 & 3.870 & 0.001 \\
$\mathrm{NO}_{2}$ & 0.144 & -0.0038 & 0.0622 & 2.372 & 0.010 \\
\hline
\end{tabular}

the ESDA analysis can assist in identifying possible spatial relationships between clusters or unobserved heterogeneity effects associated with the traffic air pollution and corresponding traffic zones. For further insights with regard to possible sources and statistical implications of unobserved heterogeneity see: Mannering et al., 2016; Fountas and Anastastopoulos, 2017; Fountas et al., 2018a; Cai et al., 2018; Fountas et al., 2018b; Mannering, 2018; Fountas and Anastasopoulos, 2018; Aguero-Valverde, 2018; Fountas and Rye, 2019; Pantangi et al., 2019, Fountas et al., 2019; Barbour et al., 2019.

\subsection{Damage costs of emissions}

Due to the inclusion of daytime traffic flows in the database, the projected costs reflect daytime flows across business days on a yearly basis (i.e., 240 days/year). The emissions were weighted on the basis of 1 peak hour and 11 hours representing the average daytime flow; as such, 12 hours per day were considered in total. Table 7 presents a compilation of damage cost values by each pollutant considered in this study. Various organizations as well as previous studies have suggested several cost ranges as reference values (to name a few, NZTA, 2013, Austroads, UK-DEFRA, 2015, European Commission, AEA, Krewitt et al., 1999; Rabl and Spadaro, 2000; Rabl et al. 2005; Mirasgedis et al. 2008; Gu et al., 2012). To avoid possible overestimation of the damage cost, we employed values corresponding to the lower limits of the reference ranges that were provided in Table 1. Table 7 summarizes the exact values that were used in this study.

Table 6. Compilation of marginal damage costs per ton of emissions of pollutants considered for each organization.

\begin{tabular}{|c|c|c|c|c|c|c|c|}
\hline \multirow{2}{*}{ Reference } & \multicolumn{7}{|c|}{ Values per ton } \\
\hline & \multicolumn{2}{|c|}{ CO } & \multicolumn{2}{|c|}{$\mathrm{NO}_{2}$} & \multirow{2}{*}{$\begin{array}{l}\mathbf{P M} \\
\mathrm{n} / \mathrm{a}^{5}\end{array}$} & \multirow{2}{*}{\multicolumn{2}{|c|}{$\begin{array}{c}\mathbf{S O}_{2} \\
\mathrm{n} / \mathrm{a}\end{array}$}} \\
\hline NZTA (2013) & NZD & 4.13 & NZD & $16,347.00$ & & & \\
\hline Austroads & AU\$ & 3.30 & AU\$ & 2,089.20 & $\mathrm{n} / \mathrm{a}$ & & $\mathrm{n} / \mathrm{a}$ \\
\hline UK-DEFRA, 2015 & \multicolumn{2}{|c|}{$\mathrm{n} / \mathrm{a}$} & $£$ & $8,417.00$ & $£ 51.881,00$ & E & $1,581.00$ \\
\hline European Commission & \multicolumn{2}{|c|}{$\mathrm{n} / \mathrm{a}$} & $€$ & $2,500.00$ & $\mathrm{n} / \mathrm{a}$ & $€$ & $3,700.00$ \\
\hline AEA (Europe average) & \multicolumn{2}{|c|}{$\mathrm{n} / \mathrm{a}$} & $€$ & $4,107.14$ & $\mathrm{n} / \mathrm{a}$ & $€$ & $5,367.86$ \\
\hline
\end{tabular}

\section{Results}

\subsection{Exploratory spatial data analysis (ESDA)}

Table 8 shows that the Moran's I was found to vary from 0.103 to 0.264 , depending on the pollutant type. For all the pollutant types, the p-value is equal to 0.05 or less, implying that homogeneous traffic zones with similar emission rates are spatially clustered (positive autocorrelation) with greater than $95 \%$ level of confidence.

Table 7. Moran's I results for each pollutant.

Figure 6 and Figure 7 and provides the Moran's $I$ scatterplots along with maps of the study area. Both Figures show the spatial dependence patterns of pollutants per intersection.

\footnotetext{
${ }^{5}$ Not applicable. Blank cells indicate that the institution has not provided applicable values for the specific pollutant.
} 
Specifically, the first (upper-right) quadrant HH (High-High) of the scatterplot shows zones with high values of pollutant emissions surrounded by zones with high values of pollutants. The second quadrant LH (Low-High) shows zones with low values of pollutant emissions surrounded by zones with high values of pollutant emissions. The third quadrant LL (LowLow) illustrates zones with low pollutant rates surrounded by zones with low rates of pollutants, whereas the fourth quadrant HL (High-Low) depicts zones with high rates of pollutants surrounded by zones with low rates. Quadrants $\mathrm{HH}$ and LL exhibit positive spatial autocorrelation indicating, thus, spatial clustering of similar magnitude and sign. In opposite manner, quadrants LH and HL exhibit negative spatial autocorrelation reflecting spatial clustering of opposite magnitude and sign.

The spatial autocorrelation of the pollutant dispersion provides evidence of low concentrations in zones of low potential for trip generation (i.e., low-order homogeneous traffic zones). These zones mainly form the cluster LL of neighboring areas, which are associated with low concentration values for the pollutants $\mathrm{CO}, \mathrm{SO}_{2}$, and $\mathrm{NO}_{2}$. Interestingly, in peripheral areas of the city, there is a predominance of low-level roads and areas of low population density; the latter factors may reduce the potential for pollutant generation. An inverse relationship between trip generation potential and pollutant concentrations was observed in the cluster LH, where low concentrations of pollutants are associated with high-order homogeneous traffic zones. This may be attributed to the significant presence of roads with less intense flow patterns (i.e., roads of lower hierarchy) in the specific zones. The opposite is observed in the HL cluster, with points of high pollutant concentrations being located in low-order homogeneous traffic zones. This finding may be capturing the relatively high traffic flows in roadways of higher road hierarchy.

Regarding the high-high $(\mathrm{HH})$ pattern of autocorrelation, the largest cluster formation was observed for the $\mathrm{SO}_{2}$ pollutant, with four points of high correlation being identified in a high-order homogeneous traffic zone ${ }^{6}$. In addition, a $\mathrm{HH}$ cluster was observed for the particulate matter with three points of high correlation as well as for the CO with one point of high correlation. Those areas coincide with the southwest portion of the municipality consisting of densely populated areas with high-flow road network. In contrast, about 30 intersections (60\% of the total) were not found to have statistically significant autocorrelation. This can be attributed to the absence of a relationship between neighboring intersections in terms of pollutant emissions. In these areas, there is a diversity of land uses, while the presence of different HTZ types and vehicles flows is evident. The diverse nature of these factors may not allow the establishment of clusters with similar patterns.

The results of the exploratory spatial data analysis showed that intersections located in major roads near high-dense traffic zones might constitute hot spots of air pollution, as indicated by the strong, positive spatial autocorrelation. This finding is intuitive since these areas are subject to the effect of traffic congestion, traffic flows fluctuations as well as their air pollutionrelated implications. Overall, this appraisal provides a preliminary, yet descriptive overview of the underlying spatial effects, with the identification of the specific sources of spatial

\footnotetext{
${ }^{6}$ In Figure 7, red points indicate sources of high pollutant concentrations, which are also highly correlated.
} 
528 heterogeneity warranting further investigation, possibly through spatial econometric modeling 529 approaches (Fountas et al., 2018c; Cai et al., 2018; Aguero-Valverde, 2018).
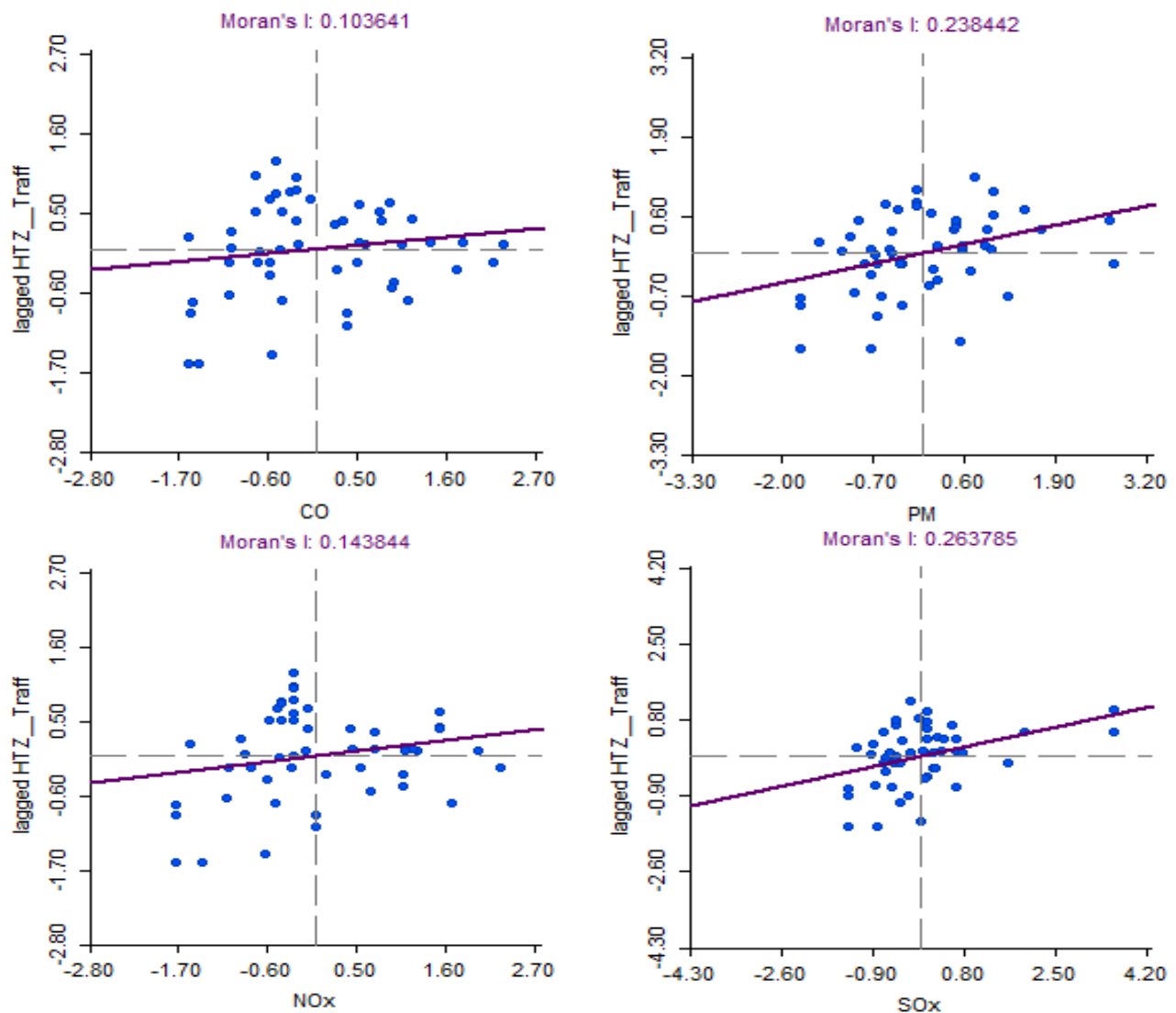

531 Figure 6. Moran's I Scatterplot for pollutants $\mathrm{CO}, \mathrm{PM}, \mathrm{NO}_{2}$ and $\mathrm{SO}_{2}$. 
532

533

534

\section{5}

536

537

538

539

540

541

542

543
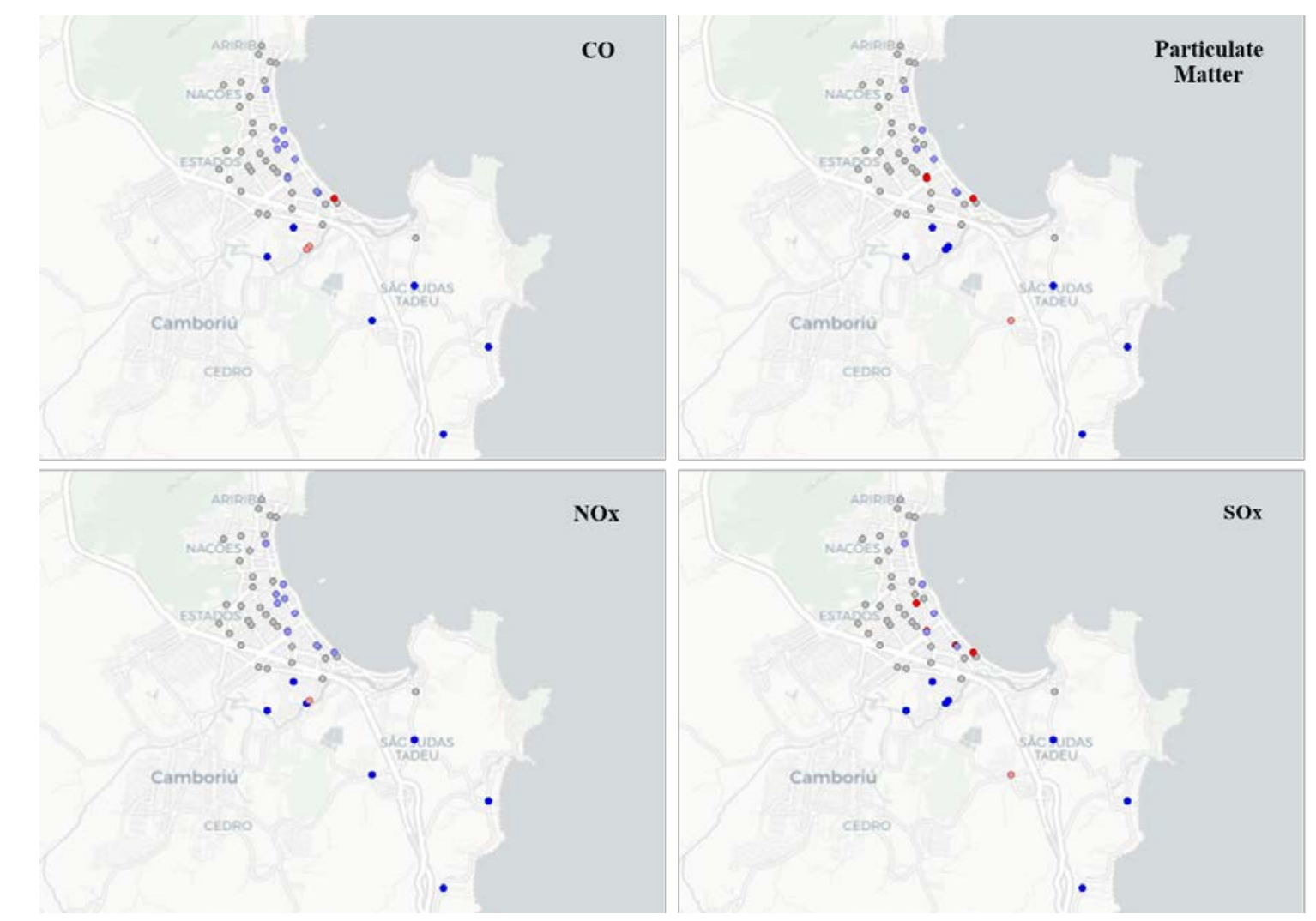

Figure 7. Moran's I map for CO, Particulate Matter, $\mathrm{NO}_{2}$ and $\mathrm{NO}_{2}$ pollutants.

\subsection{Emission rate and concentration of pollutants}

The emission rates of pollutants constitutes a fundamental cohort of results, since it serves as the input for the calculation of the concentrations of the studied pollutants. These rates were calculated for each type of intersection; note that a total of 25 types of intersections were identified using the road hierarchy and the homogeneous traffic zones as defining criteria (see Table 9 for a comprehensive overview of the emission rates per intersection type).

Table 8. Emission rates of pollutants (E) per Homogeneous Traffic Zone (HTZ) and Road Hierarchy.

\begin{tabular}{|c|c|c|c|c|c|c|c|c|c|c|c|}
\hline \multirow{3}{*}{ HTZ } & \multirow{3}{*}{$\begin{array}{c}\text { Road } \\
\text { Hierarchy }\end{array}$} & \multicolumn{5}{|c|}{ Peak Hour } & \multicolumn{5}{|c|}{ Average Daytime Hour } \\
\hline & & \multirow{2}{*}{ Veh/h } & \multicolumn{4}{|c|}{ Emission rate $E(\mathrm{Kg} / \mathrm{h})$} & \multirow{2}{*}{ Veh/h } & \multicolumn{4}{|c|}{ Emission rate - $E(\mathrm{Kg} / \mathrm{h})$} \\
\hline & & & $\mathrm{CO}$ & $\mathrm{NO}_{2}$ & MP & $\mathrm{SO}_{2}$ & & CO & $\mathrm{NO}_{2}$ & MP & $\mathrm{SO}_{2}$ \\
\hline \multirow{5}{*}{1} & A1 & 710 & 0.0260 & 0.0130 & 0.00029 & 0.0046 & 547 & 0.0201 & 0.0117 & 0.00025 & 0.0035 \\
\hline & A2 & 772 & 0.0283 & 0.0142 & 0.00032 & 0.0050 & 375 & 0.0138 & 0.0080 & 0.00017 & 0.0024 \\
\hline & $\mathrm{C} 1$ & 575 & 0.0211 & 0.0106 & 0.00024 & 0.0037 & 462 & 0.0170 & 0.0099 & 0.00022 & 0.0030 \\
\hline & $\mathrm{C} 2$ & 297 & 0.0109 & 0.0055 & 0.00012 & 0.0019 & 180 & 0.0066 & 0.0039 & 0.00008 & 0.0012 \\
\hline & $\mathrm{L}$ & 18 & 0.0007 & 0.0003 & 0.00001 & 0.0001 & 10 & 0.0004 & 0.0002 & 0.00000 & 0.0001 \\
\hline \multirow{5}{*}{2} & A1 & 837 & 0.0307 & 0.0154 & 0.00035 & 0.0054 & 621 & 0.0228 & 0.0133 & 0.00029 & 0.0040 \\
\hline & A2 & 773 & 0.0283 & 0.0142 & 0.00032 & 0.0050 & 429 & 0.0158 & 0.0092 & 0.00020 & 0.0028 \\
\hline & C1 & 611 & 0.0224 & 0.0112 & 0.00025 & 0.0039 & 458 & 0.0168 & 0.0098 & 0.00021 & 0.0030 \\
\hline & $\mathrm{C} 2$ & 463 & 0.0170 & 0.0085 & 0.00019 & 0.0030 & 343 & 0.0126 & 0.0073 & 0.00016 & 0.0022 \\
\hline & $\mathrm{L}$ & 144 & 0.0053 & 0.0026 & 0.00006 & 0.0009 & 95 & 0.0035 & 0.0020 & 0.00004 & 0.0006 \\
\hline \multirow{5}{*}{3} & A1 & 788 & 0.0289 & 0.0145 & 0.00033 & 0.0051 & 586 & 0.0215 & 0.0126 & 0.00027 & 0.0038 \\
\hline & A2 & 791 & 0.0290 & 0.0145 & 0.00033 & 0.0051 & 477 & 0.0175 & 0.0102 & 0.00022 & 0.0031 \\
\hline & C1 & 704 & 0.0258 & 0.0129 & 0.00029 & 0.0045 & 520 & 0.0191 & 0.0112 & 0.00024 & 0.0034 \\
\hline & $\mathrm{C} 2$ & 419 & 0.0154 & 0.0077 & 0.00017 & 0.0027 & 275 & 0.0101 & 0.0059 & 0.00013 & 0.0018 \\
\hline & $\mathrm{L}$ & 100 & 0.0037 & 0.0018 & 0.00004 & 0.0006 & 82 & 0.0030 & 0.0018 & 0.00004 & 0.0005 \\
\hline
\end{tabular}




\begin{tabular}{|c|c|c|c|c|c|c|c|c|c|c|c|}
\hline \multirow{3}{*}{ HTZ } & \multirow{3}{*}{$\begin{array}{c}\text { Road } \\
\text { Hierarchy }\end{array}$} & \multicolumn{5}{|c|}{ Peak Hour } & \multicolumn{5}{|c|}{ Average Daytime Hour } \\
\hline & & \multirow{2}{*}{ Veh/h } & \multicolumn{4}{|c|}{ Emission rate $E(\mathrm{Kg} / \mathrm{h})$} & \multirow{2}{*}{ Veh/h } & \multicolumn{4}{|c|}{ Emission rate - $E(\mathrm{Kg} / \mathrm{h})$} \\
\hline & & & CO & $\mathrm{NO}_{2}$ & MP & $\mathrm{SO}_{2}$ & & CO & $\mathrm{NO}_{2}$ & MP & $\mathrm{SO}_{2}$ \\
\hline \multirow{5}{*}{4} & A1 & 795 & 0.0292 & 0.0146 & 0.00033 & 0.0051 & 644 & 0.0237 & 0.0138 & 0.00030 & 0.0041 \\
\hline & $\mathrm{A} 2$ & 739 & 0.0271 & 0.0136 & 0.00031 & 0.0048 & 550 & 0.0202 & 0.0118 & 0.00026 & 0.0035 \\
\hline & C1 & 486 & 0.0178 & 0.0089 & 0.00020 & 0.0031 & 450 & 0.0165 & 0.0096 & 0.00021 & 0.0029 \\
\hline & $\mathrm{C} 2$ & 444 & 0.0163 & & 0.00018 & 0.0029 & 334 & 0.0123 & 0.0072 & 0.00016 & 0.0022 \\
\hline & $\mathrm{L}$ & 165 & 0.0060 & 0.0030 & 0.00007 & 0.0011 & 135 & 0.0050 & 0.0029 & 0.00006 & 0.0009 \\
\hline \multirow{5}{*}{5} & A1 & 1,042 & 0.0382 & 0.0191 & 0.00043 & 0.0067 & 734 & 0.0270 & 0.0157 & 0.00034 & 0.0047 \\
\hline & A2 & 793 & 0.0291 & 0.0146 & 0.00033 & 0.0051 & 585 & 0.0215 & 0.0125 & 0.00027 & 0.0038 \\
\hline & C1 & 775 & 0.0284 & 0.0142 & 0.00032 & 0.0050 & 514 & 0.0189 & 0.0110 & 0.00024 & 0.0033 \\
\hline & $\mathrm{C} 2$ & 446 & 0.0164 & 0.0082 & 0.00018 & 0.0029 & 341 & 0.0125 & 0.0073 & 0.00016 & 0.0022 \\
\hline & $\mathrm{L}$ & 146 & 0.0053 & 0.0027 & 0.00006 & 0.0009 & 98 & 0.0036 & 0.0021 & 0.00005 & 0.0006 \\
\hline
\end{tabular}

544

545

546

547

548

549

550

551

552

553

554

555

556

557

558

559

560

The modeling results have shown that $\mathrm{NO}_{2}, \mathrm{SO}_{2}$, and $\mathrm{CO}$ are the pollutants that exceed the limits of air quality legislation. It should be noted that the estimated values come from simulated data rather than from a primary data collection; thus, such estimated concentrations serve as reference values within the context of a preliminary investigation of air pollution levels, since there is no emission data available, nor any monitoring program, to the study area.

These concentrations derived by the model are mainly observed up to 20 meters (approximately) from the road network, with the peak of concentrations being observed at a distance near 10 meters from the road network. At this distance, for example, about $60 \%, 71 \%$ and $41 \%$ of the intersections during the peak hours are associated with concentrations exceeding the thresholds, for $\mathrm{NO}_{2}, \mathrm{SO}_{2}$, and $\mathrm{CO}$, respectively; the same is observed for $50 \%$ and $65 \%$ of the intersections during the average daytime hours, for $\mathrm{SO}_{2}$ and $\mathrm{NO}_{2}$, respectively (see also Figure $8-11$ ). The 20 -year projections show that $61 \%, 83 \%$ and $58 \%$ of the intersections during peak hours (for $\mathrm{NO}_{2}, \mathrm{SO}_{2}$, and $\mathrm{CO}$, respectively), and $53 \%$ and $83 \%$ of the intersections during daytime average hours (for $\mathrm{NO}_{2}$ and $\mathrm{SO}_{2}$, respectively) are associated with exceeding concentrations. It is worthwhile to mention that local roads, and, in some districts, secondary collector roads do not generally exhibit concentrations over legislation thresholds.
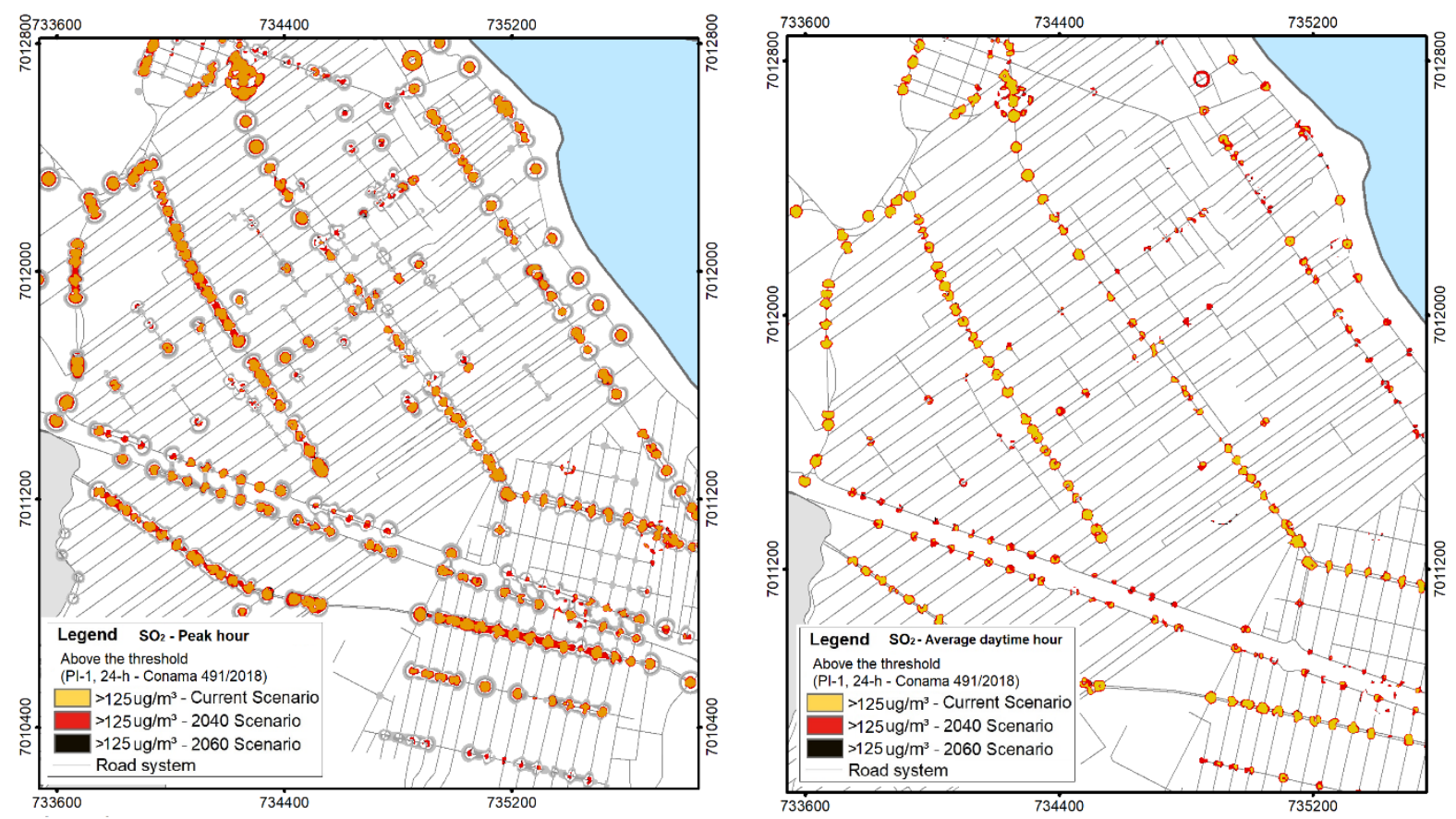
Figure 8. Map of $\mathrm{SO}_{2}$ concentrations for the average daytime and peak hour.
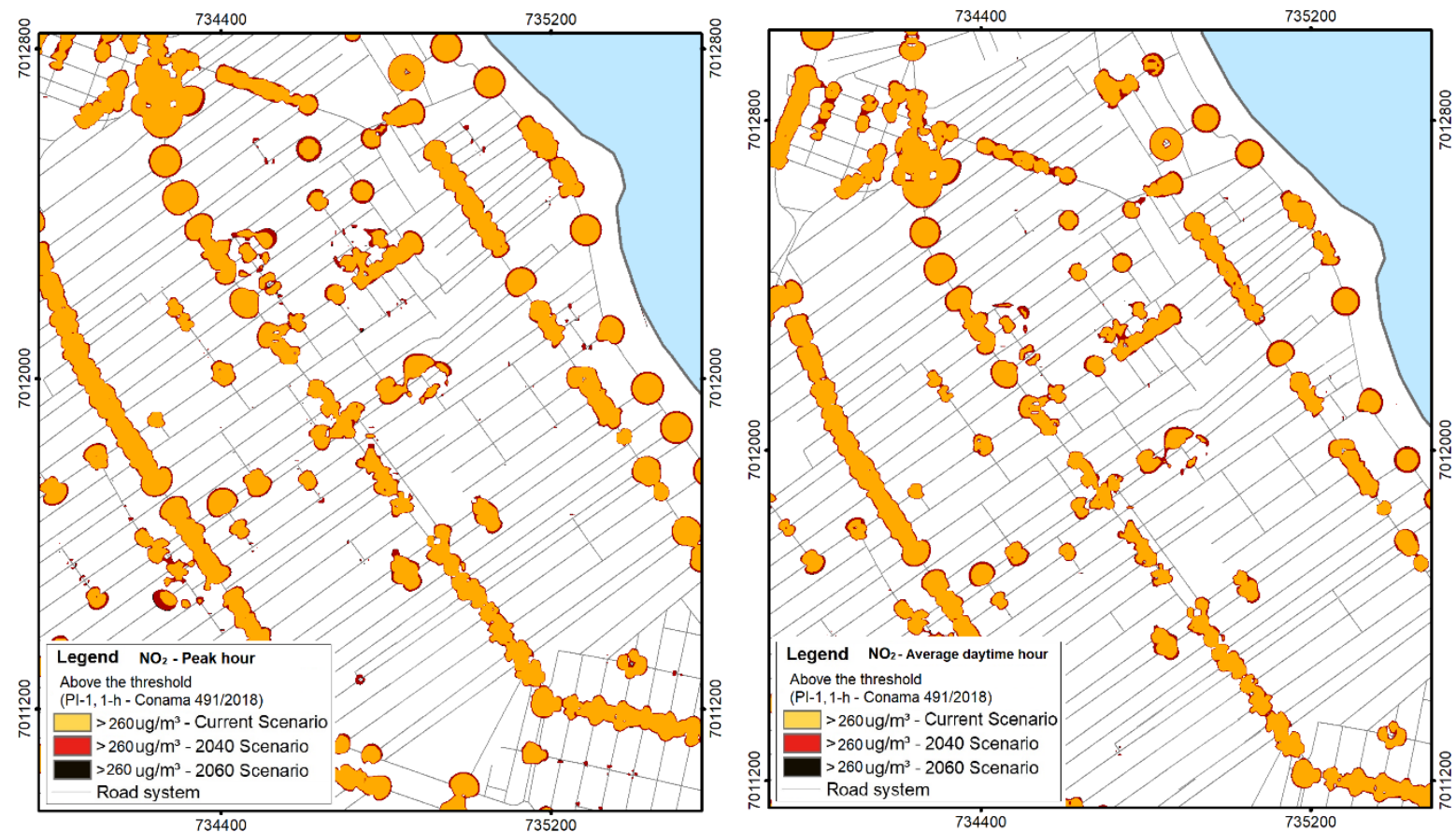

Figure 9. Map of $\mathrm{NO}_{2}$ concentration for the average daytime and peak hour.

The upper limits of concentrations were not reached by the contaminant Particulate was about $26 \mu \mathrm{g} / \mathrm{m}^{3}$ (the considered upper limit was $240 \mu \mathrm{g} / \mathrm{m}^{3}$ - see Figure 11 for a mapping overview of the concentrations).
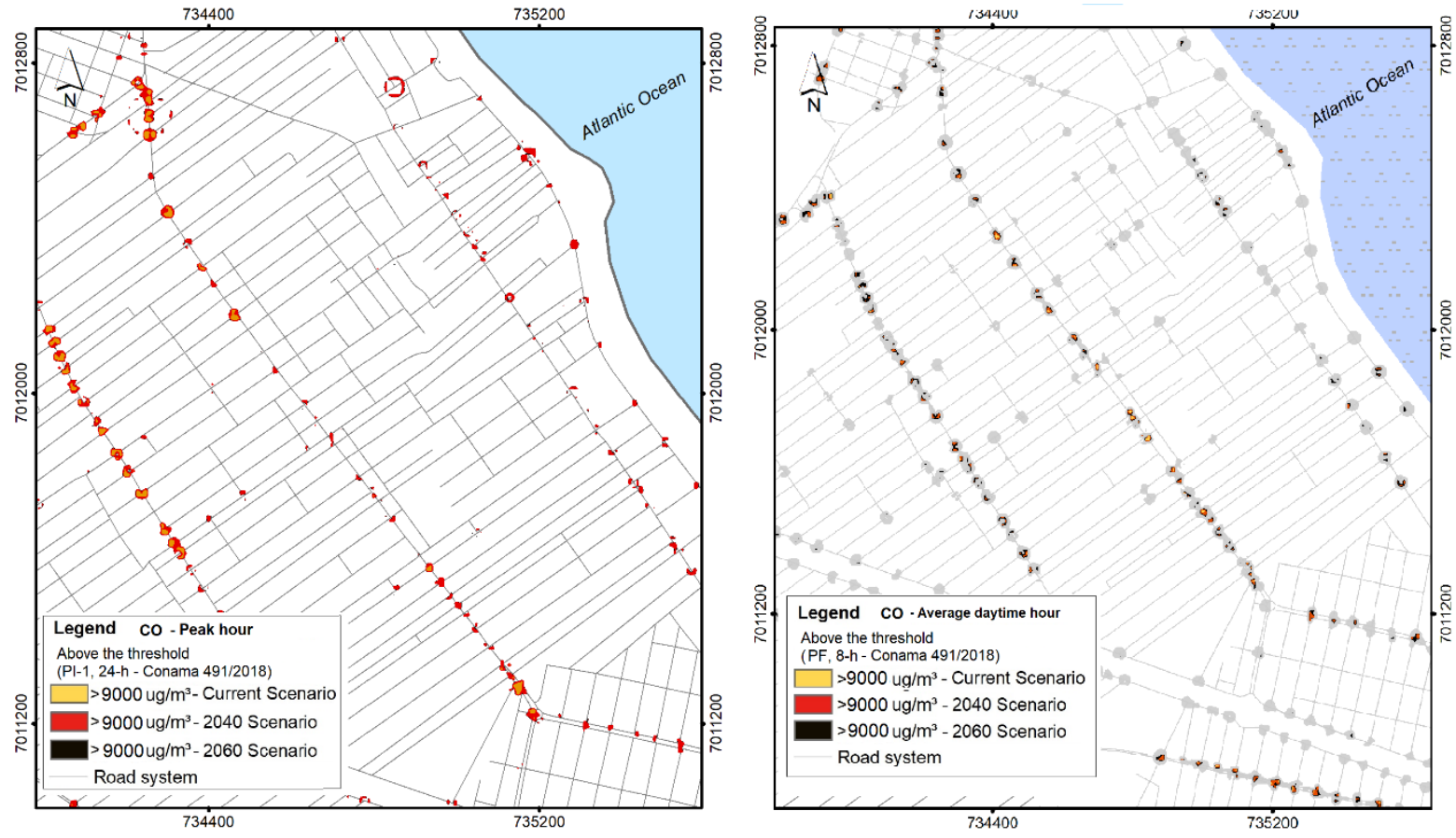

573 Figure 10. Map of CO concentration for the average daytime and peak hour. 
575

576

577

578

579

580

581

582

583

584

585

586

587

588

589

590

591

592

593

594

595

596

597

598
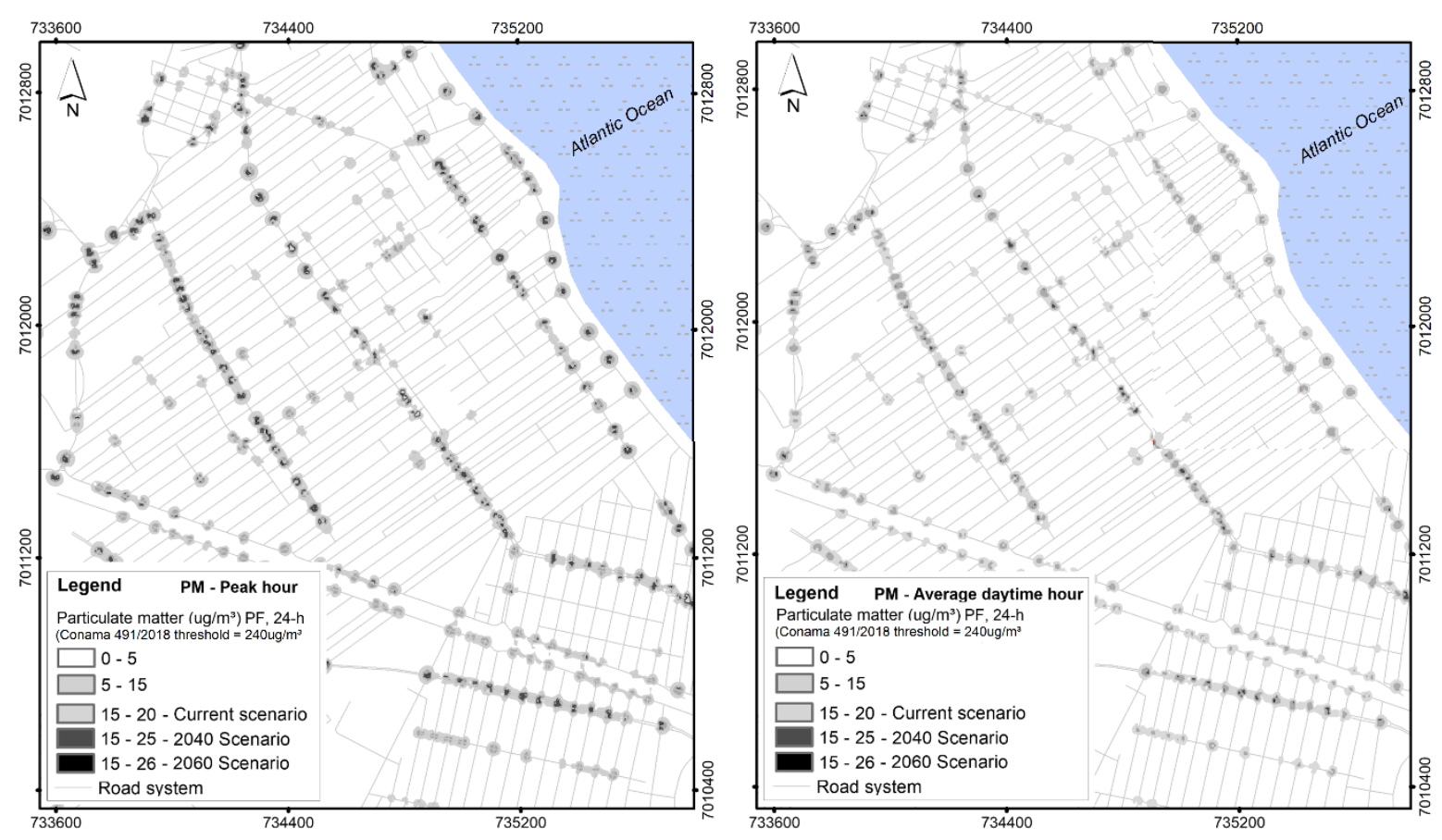

Figure 11. Map of Particulate Matter (PM) concentration for the average daytime and peak hour.

Table 10 presents the areas affected by pollutants that exceed the primary quality standards (i.e., $\mathrm{SO}_{2}$ and $\mathrm{NO}_{2}$ ) and are liable to cause damage to the population's health. An area of about 1.45 million $\mathrm{m}^{2}$ was estimated to be affected by $\mathrm{SO}_{2}$ during peak hours; for $\mathrm{NO}_{2}$, the corresponding estimate is about 4.86 million $\mathrm{m}^{2}$, and for CO, 0.21 million $\mathrm{m}^{2}$. During average daytime hours, an area of 0.71 million $\mathrm{m}^{2}$ was estimated to be affected by $\mathrm{SO}_{2}$, whereas an area of 4.03 million $\mathrm{m}^{2}$ was estimated to be affected by $\mathrm{NO}_{2}$. The estimates for future scenarios indicate a mixed growth trend for the affected areas, possibly due to the projected rate of increase in traffic flows. Focusing on the $\mathrm{SO}_{2}$ emissions during peak hours, the growth rate of the affected areas is around $87.4 \%$ considering the 20 -year scenario, whereas for the remaining 20 years of the 40 -year scenario, the growth rate decreases to $3.4 \%$. During the average daytime hours, the affected area increases approximately $109.1 \%$ for $\mathrm{SO}_{2}$ and $29.1 \%$ for $\mathrm{NO}_{2}$, considering the 20-year scenario. For the remaining 20 years of the 40 -year scenario, the affected area increases by $5.2 \%$ for $\mathrm{SO}_{2}$ and by $1.9 \%$ for $\mathrm{NO}_{2}$.

The identified affected areas are adjacent to the road network, with the emissions arising from the latter having a direct impact on the adjacent households, in terms of possible health burden. Considering a reference size of $300 \mathrm{~m}^{2}$ per property (PMBC, 1974), it is estimated that approximately $1.0 \mathrm{k}$ households are exposed to excessive emissions of $\mathrm{SO}_{2}$, approximately $4.6 \mathrm{k}$ households are exposed to excessive emissions of $\mathrm{NO}_{2}$, and 72 households are exposed to excessive emissions of $\mathrm{CO}$, during peak hours. During the average daytime hours, approximately 445 and $3.7 \mathrm{k}$ households are exposed to excessive emissions of $\mathrm{SO}_{2}$ and $\mathrm{NO}_{2}$, respectively (see also Table 10 for the exact values). 
599

600

601

Table 9. Estimated area and number of households affected by pollutants exceeding legislative thresholds.

\begin{tabular}{|c|c|c|c|c|c|c|c|}
\hline \multirow[b]{2}{*}{ Pollutant } & \multirow[b]{2}{*}{ Scenario: 2040} & \multicolumn{3}{|c|}{ Peak hour } & \multicolumn{3}{|c|}{ Average daytime hour } \\
\hline & & $\begin{array}{l}\text { Affected } \\
\text { area }\left(\mathrm{m}^{2}\right)\end{array}$ & $\%$ variation & $\begin{array}{c}\text { Affected } \\
\text { properties* }\end{array}$ & $\begin{array}{l}\text { Affected } \\
\text { area }\left(\mathbf{m}^{2}\right)\end{array}$ & $\%$ variation & $\begin{array}{c}\text { Affected } \\
\text { properties* }\end{array}$ \\
\hline \multirow{3}{*}{$\mathrm{SO}_{2}$} & Current & 302,090 & - & 1,007 & 133,556 & - & 445 \\
\hline & Scenario: 2040 & 566,202 & $87.4 \%$ & 1,887 & 279,320 & $109.1 \%$ & 931 \\
\hline & Scenario: 2060 & 585,449 & $3.4 \%$ & 1,951 & 293,883 & $5.2 \%$ & 980 \\
\hline \multirow{3}{*}{$\mathrm{NO}_{2}$} & Current & 1405515 & & 4.685 & $1,116,866$ & - & 3,723 \\
\hline & Scenario: 2040 & 1714966 & $20.2 \%$ & 5.717 & $1,441,874$ & $29.1 \%$ & 4,806 \\
\hline & Scenario: 2060 & 1743421 & $1.5 \%$ & 5.811 & $1,469,070$ & $1.9 \%$ & 4,897 \\
\hline \multirow{3}{*}{$\mathrm{CO}$} & Current & 21,715 & - & 72 & - & - & - \\
\hline & Scenario: 2040 & 93,067 & $328.6 \%$ & 310 & - & - & - \\
\hline & Scenario: 2060 & 102,844 & $10.5 \%$ & 343 & - & - & - \\
\hline
\end{tabular}

* A typical area size of urban property is considered equal to $300 \mathrm{~m}^{2}$.

603

604

605

606

607

608

609

610

611

612

613

614

615

616

\subsection{Damage costs of the emissions}

Table 11 provides the calculated damage costs per pollutant for the current and future scenarios. The pollutants with the highest damage values are $\mathrm{NO}_{2}, \mathrm{PM}, \mathrm{SO}_{2}$, and $\mathrm{CO}$ (the rank implies a descending order). The total damage cost is approximately equal to US\$ 886k for the current scenario. For the 20-year time horizon, the total cost is expected to increase to approximately US\$ $1,381 \mathrm{k}$ per year, possibly due to the accelerated growth of vehicle fleet, whereas it does stabilize in the long run (40-year horizon) to approximately US\$1,433k per year.

Despite their preliminary nature, such damage cost values highlight the need for a deeper investigation of the methodological approaches focusing on their calculation and evaluation. However, what it can be inferred from this preliminary analysis, is that these values reflect a high social cost, which goes far beyond the purely economic value and more importantly, involves direct implications on the quality of life and level of health of the urban population.

Table 10. Damage costs results (in US\$)

\begin{tabular}{lccccr}
\hline \multirow{2}{*}{ Scenario } & \multicolumn{5}{c}{ Damage Cost (US\$) per year per pollutant } \\
\cline { 2 - 6 } & $\mathbf{C O}$ & $\mathbf{N O}_{2}$ & $\mathbf{P M}$ & $\mathbf{S O}_{2}$ & \multicolumn{1}{c}{ Total } \\
\hline Current & $\$ 1,096.07$ & $\$ 396,192.26$ & $\$ 387,987.69$ & $\$ 101,212.62$ & $\$ 886,488.64$ \\
Future 2040 & $\$ 1,707.84$ & $\$ 617,327.23$ & $\$ 604,543.59$ & $\$ 157,704.87$ & $\$ 1,381,283.53$ \\
Future 2060 & $\$ 1,772.42$ & $\$ 640,669.46$ & $\$ 627,402.45$ & $\$ 163,667.96$ & $\$ 1,433,512.28$ \\
\hline
\end{tabular}

\section{Summary and Conclusions}

This study provides a comprehensive, yet preliminary approach towards the quantification and evaluation of air pollution patterns from mobile, transportation-related sources. This integrated approach may contribute to the municipal environmental management and the formulation of public policies as well as support the decision making process of Public Authorities, especially from an environmental and economic perspective. The potential of this approach to approximate the extent of the population's exposure to possible environmental and health risks using very limited data highlights its applicability in urban settings lacking systematic monitoring of the transportationrelated air pollution. The city of Balneário Camboriú, Brazil falls within this category, as such, the evaluation of its air pollution dynamics formed the basis for the development of this integrated approach.

With regard to the outcomes of this approach, the generation of dispersion maps of pollutant concentrations allows the initial evaluation of strategies for the improvement of urban air quality. 
Since urban traffic constitutes a significant determinant of the air pollution patterns, remedies for air pollution reduction should also account for separate or interrelated sources of pollution within the transportation network. To that end, spatial autocorrelations of air pollution were also identified, where the clustering of various urban districts with similar air pollution patterns was found to be interrelated with the presence of homogeneous traffic zones. Even though the spatial autocorrelation analysis cannot thoroughly explain the underlying mechanism of the spatial dependence, it does provide a preliminary identification of the sources that may induce spatial heterogeneity (such as, land use activities, interactive effect of congestion and road hierarchy, diversity of activities across homogeneous traffic zones). Furthermore, the spatial dependence patterns can shed more light on possible "hotspots" of air pollution that need to be addressed by local policies.

It should be mentioned that the findings of this study have intrinsic limitations, which should be carefully considered by traffic and environmental modellers when interpreting them. The need for extrapolation of the traffic flows to the entire network, the use of mathematical models and reference values that allow a satisfying, yet empirical approximation of the transportation-generated externalities constitute some of these limitations. However, all these limitations stem from the very limited availability of environmental and transportation data, which is commonly observed in the developing countries of Latin America. In this context, this work should be viewed as a methodological alternative for assessing the air pollution dynamics using aggregate data; the findings of this assessment can potentially serve as input for appraisals of the health implications of transportation-related activities.

Despite its potential, the evaluation of the aggregate patterns of air pollution cannot provide practice-ready insights to stakeholders and public Agencies without an a priori quantification of the interrelationship between various public health aspects and externalities of transportation. In Brazil, this quantification can be expressed in terms of reference values of emissions at a state or country level, with the specification of these values requiring deeper and more disaggregate analyses. Using detailed datasets of real-time traffic flows and emissions, future endeavors can lead not only to the validation or modification of the findings of the specific study but also to significant methodological and empirical advances. The latter may include the application of more robust modeling approaches (e.g., spatial econometric models), the provision of more accurate predictions and the identification of effective countermeasures for areas susceptible to transportation-generated air pollution.

\section{Acknowledgements}

The research presented in this paper was funded by the Brazilian Ministry of Education, Capes, Brazil-PDSE, Process nº 88881.187746/2018-01.

\section{Bibliographic references}

AEA-TE., 2005. AEA Technology Environment. Damages per tonne emission of $\mathrm{PM}_{2,5}, \mathrm{NH}_{3}$, $\mathrm{SO}_{2}, \mathrm{NO}_{2}$ and VOCs from each EU25 Member State (excluding Cyprus) and surrounding seas. Service Contract for Carrying out Cost-Benefit Analysis of Air Quality Related Issues, in particular in the Clean Air for Europe (CAFE) Programme.

Aguero-Valverde, J., 2018. Jointly Specified Spatial Priors for Bayesian Models of Crash Frequency. Transportation Research Record, 2672(30), 90-98.

Alves, C. A., Gomes, J., Nunes, T., Duarte, M., Calvo, A., Custódio, D., Pio, C.; Karanasiou, A.; Querol, X., 2015. Size-segregated particulate matter and gaseous emissions from motor vehicles in a road tunnel. Atmospheric Research, 153, 134-144. 
Andrade, M., Kumar, P., de Freitas, E.D., Ynoue, R.Y., Martins, J., Martins, L.D., Nogueira, T., Perez-Martinez, P., de Miranda, R.M., Albuquerque, T., Gonçalves, F.L.T., 2017. Air quality in the megacity of São Paulo: Evolution over the last 30 years and future perspectives. Atmospheric environment, 159, 66-82.

ANP - Agência Nacional de Petróleo, Gás Natural e Biocombustíveis. Dados estatísticos: vendas de combustíveis no ano de 2016.

Anastasopoulos, P. Ch., Florax, R. J. G. M., Labi, S., Karlaftis, M. G., 2010. Contracting in highway maintenance and rehabilitation: Are spatial effects important? Transportation Research Part A, 44, 136-146.

Anastasopoulos, P.Ch., Fountas, G., Sarwar, M.T., Karlaftis, M.G., Sadek, A.W., 2017. Transport habits of travelers using new energy type modes: a random parameters hazard-based approach of travel distance. Transportation Research Part C: Emerging Technologies, 77, 516-528.

Anselin, L., 1996. The Moran Scatterplot as an ESDA Tool to Assess Local Instability in Spatial Association. Spatial Analytical Perspectives on Gis in Environmental and Socio-Economic Sciences. 111-25. London: Taylor; Francis.

Anselin, L. 2018. Contiguity-Based Spatial Weights. Available in: <https://geodacenter.github.io/workbook/4a_contig_weights/lab4a.html>. Accessed in 19/11/2018.

Araujo, S. A., Scolaro, T. L., Reis, F. H., Petermann, R. M., 2009. Climatologia do ecossistema Saco da Fazenda, Itajaí, SC., 43-62p. In: Joaquim Olinto Branco; Maria José LunardonBranco \& Valéria Regina Bellotto (Org.). Estuário do Rio Itajaí-Açú, Santa Catarina: caracterização ambiental e alterações antrópicas. Editora UNIVALI, Itajaí, SC., 312p.

ARCGIS, 2018. How Natural Neighbor works. Available at: http://desktop.arcgis.com/en/arcmap/10.3/tools/spatial-analyst-toolbox/how-natural-neighborworks.htm. Accessed: 26/09/2018.

Austroads, 2012. Guide to Project Evaluation Part 4: Project Evaluation Data. Available in: <https://ngtsmguidelines.files.wordpress.com/2014/08/agpe04-12.pdf>. Acessed in 12/12/2018.

Barbour, N., Zhang, Y., Mannering, F., 2019. A statistical analysis of bike sharing usage and its potential as an auto-trip substitute. Journal of Transport \& Health, 12, 253-262.

Berkowicz, R., Winther, M., Ketzel, M., 2006. Traffic pollution modelling and emission data. Environmental Modelling \& Software, 21(4), 454-460.

Bigazzi, A. Y., Rouleau, M., 2017. Can traffic management strategies improve urban air quality? A review of the evidence. Journal of Transport \& Health, 7, 111-124.

Borge, R., Miguel, I., Paz, D., Lumbreras, J., 2012. Comparison of road traffic emission models in Madrid (Spain). Atmospheric Environment, 62, 461-471.

Boulter, P. G., McCrae, I. S., Barlow, T. J., 2007. A review of instantaneous emission models for road vehicles. Transport Research Laboratory, TRL.

Brazil, 1986. Resolução Conama 18, de 6 de maio de 1986. Dispõe sobre a criação do Programa de Controle de Poluição do Ar por veículos Automotores - Proconve. Brasília, 1986.

Brazil, 1990. Resolução Conama 491 de 19 de novembro de 2018. Dispõe sobre os padrões de qualidade do ar. Brasília, 2018.

Brazil, 1993. Resolução Conama 005 de 5 de agosto de 1993. Dispõe sobre o Programa Nacional de Controle da Poluição do Ar - PRONAR. Brasília, 1989. 
Briggs, D. J., 2000. A regression-based method for mapping traffic-related air pollution: application and testing in four contrasting urban environments. Science of the Total Environment, 253(1-3), 151-167.

Bukowiecki, N., Lienemann, P., Hill, M., Furger, M., Richard, A., Amato, F., Prévôt, A.S.H., Baltensperger, U., Buchmann, B., Gehrig, R., 2010. PM10 emission factors for non-exhaust particles generated by road traffic in an urban street canyon and along a freeway in Switzerland. Atmospheric Environment, 44(19), 2330-2340.

Cai, Q., Abdel-Aty, M., Lee, J., Wang, L., Wang, X., 2018. Developing a grouped random parameters multivariate spatial model to explore zonal effects for segment and intersection crash modeling. Analytic Methods in Accident Research, 19, 1-15.

Çapraz, Ö., Efe, B., Deniz, A., 2016. Study on the association between air pollution and mortality in İstanbul, 2007-2012. Atmospheric Pollution Research, 7(1), 147-154.

CETESB - Companhia Ambiental do Estado do São Paulo, 2009. Qualidade do Ar no Estado de São Paulo. Governo do estado de São Paulo. Secretaria do Meio Ambiente. São Paulo.

CETESB - Companhia Ambiental do Estado de São Paulo, 2017. Emissões veiculares no estado de São Paulo 2016. Governo do Estado de São Paulo - Secretaria do Meio Ambiente. Set-17.

Costabile, F., Allegrini, I., 2008. A new approach to link transport emissions and air quality: An intelligent transport system based on the control of traffic air pollution. Environmental Modelling \& Software, 23.

DC - Diário Catarinense, 2018 Com baixa demanda, postos de Florianópolis desistem de vender etanol. Sindicato do Comércio Varejista de Combustíveis Minerais de Florianópolis Sindópolis 21/06/2018. Available: <http://dc.clicrbs.com.br/sc/noticias/noticia/2018/06/com-baixademanda-postos-de-florianopolis-desistem-de-vender-etanol-10384155.html>

DEFRA - Air Quality Appraisal - Damage Cost Methodology. Interdepartmental Group on Costs and Benefits, Air Quality Subject Group. Feb. 2011.

Derisio, J. C. Introdução ao controle de poluição ambiental. São Paulo: CETESB, 1992. 201p.

DETRAN/SC - Departamento Estadual de Trânsito de Santa Catarina, 2018. Frota de veículos por município (mensal) - desde dezembro de 2002. Available in: http://www.detran.sc.gov.br/estatisticas/266-estatistica-veiculos. Access in 28/Jul/2018.

Dey, S., Caulfield, B., Ghosh, B., 2018. Potential health and economic benefits of banning diesel traffic in Dublin, Ireland. Journal of Transport \& Health, 10, 156-166.

Fang, G.C., Lo, C.T., Zhuang, Y.J., Cho, M.H., Huang, C.Y., Xiao, Y.F., Tsai, K.H., 2017. Seasonal variations and sources study by way of back trajectories and ANOVA for ambient air pollutants (particulates and metallic elements) within a mixed area at Longjing, central Taiwan: 1year observation. Environmental geochemistry and health, 39(1), 99-108.

Fountas, G., Anastasopoulos, P.Ch., 2017. A random thresholds random parameters hierarchical ordered probit analysis of highway accident injury-severities. Analytic methods in accident research, 15, 1-16.

Fountas, G., Anastasopoulos, P.Ch., 2018. Analysis of accident injury-severity outcomes: The zero-inflated hierarchical ordered probit model with correlated disturbances. Analytic methods in accident research, 20, 30-45.

Fountas, G., Anastasopoulos, P.Ch., Mannering, F.L., 2018a. Analysis of vehicle accidentinjury severities: a comparison of segment-versus accident-based latent class ordered probit models with class-probability functions. Analytic Methods in Accident Research, 18, 15-32. 
Fountas, G., Anastasopoulos, P.Ch., Abdel-Aty, M., 2018b. Analysis of accident injuryseverities using a correlated random parameters ordered probit approach with time variant covariates. Analytic Methods in Accident Research, 18, 57-68.

Fountas, G., Sarwar, M.T., Anastasopoulos, P.Ch., Blatt, A., Majka, K., 2018c. Analysis of stationary and dynamic factors affecting highway accident occurrence: a dynamic correlated grouped random parameters binary logit approach. Accident Analysis and Prevention, 113, 330-340.

Fountas, G., Rye, T., 2019. A note on accounting for underlying injury-severity states in statistical modeling of injury accident data. Procedia Computer Science, 151, 202-209.

Fountas, G., Sonduru Pantangi, S., Hulme, K., Anastasopoulos, P.Ch., 2019. The effects of driver fatigue, gender and distracted driving on perceived and observed aggressive driving behavior: A correlated grouped random parameters bivariate probit approach. Analytic Methods in Accident Research, 22, 100091.

Getis, A., 2007. Reflections on spatial autocorrelation. Regional Science and Urban Economics, 37(4), 491-496.

Gois, V., Maciel, H., Nogueira, L., Almeida, C., Torres, P., Mesquita, S., Ferreira, F., 2007. A detailed urban road traffic emissions inventory model using aerial photography and GPS surveys. 16th Annual International Emission Inventory Conference - Emission Invent.

Gu, Ba., Ge, Y., Ren, Y., Xu, B., Luo, W., Jiang, H., Gu, Bi. Chang, J., 2012. Atmospheric Reactive Nitrogen in China: Sources, Recent Trends, and Damage Costs. Environmental Science \& Technology, 46(17), 9420-9427.

Gualtieri, G., Tartaglia, M., 1998. Predicting urban traffic air pollution: a GIS Framework. Transportation Research part D, v.3, n.5, p.329-336.

Hyland, J., Donnelly, P., 2015. Air pollution and health - The views of policy makers, planners, public and private sector on barriers and incentives for change. Journal of Transport \& Health, 2(2), 120-126.

IBAMA - Instituto Brasileiro do Meio Ambiente e dos Recursos Naturais Renováveis, 2014. Inventário Nacional de Emissões Atmosféricas por Veículos Rodoviários 2013. Jan-14.

IBGE - Instituto Brasileiro de Geografia e Estatística, 2010. Censo Demográfico 2010. Rio de Janeiro.

IBGE - Instituto Brasileiro de Geografia e Estatística, 2016. Arranjos Populacionais e Concentrações Urbanas do Brasil. 2 ed. Rio de Janeiro.

INFRAS, 2004. Handbook of emission Factors for road Transport, Version 2.1. INFRA, Berne.

Jain, S., Aggarwal, P., Sharma, P., Kumar, P., 2016. Vehicular exhaust emissions under current and alternative future policy measures for megacity Delhi, India. Journal of Transport \& Health, 3 (3), 404-412

Jerrett, M., 2005. Spatial Analysis of Air Pollution and Mortality in Los Angeles. Epidemiology, 16(6), 727-736.

Khomiakova, T., 2008. Spatial analysis of regional divergence in India: income and economic structure perspectives. The International Journal of Economic Policy Studies. v.3. article 7.

Krewitt, W., Heck, T., Trukenmüller, A., Friedrich, R., 1999. Environmental damage costs from fossil electricity generation in Germany and Europe. Energy Policy, 27(3), 173-183. 
Lacava, C. I. V., 2003. Avaliação da qualidade do ar. Capítulo 2: Emissões Atmosférica. In.: Avaliação da qualidade do ar. In: Emissões atmosféricas. p. 131 - 180.

Lautso, K., 2004. Planning and Research of Policies for Land Use and Transport for Increasing Urban Sustainability. European Commission under the Energy, Environment and Sustainable Development Thematic Programme of the Fifth RTD Framework Programme. Final Report. 2 ed.

Lin, J., Ge, Y. E., 2006. Impacts of traffic heterogeneity on roadside air pollution concentration. Transportation Research Part D: Transport and Environment, 11(2), 166-170

Lorant, V., Thomas, I., Deliège, D., Tonglet, R., 2001. Deprivation and mortality: the implications of spatial autocorrelation for health resources allocation. Social Science \& Medicine, 53(12), 1711-1719.

Londono, J., Correa, M. A., Palacia, C. A., 2011. Estimación de las emisiones de contaminantes atmosféricos provenientes de fuentes móviles en el área urbana de envigado, Colombia. Revista EIA, n.16, p. 149-162. Escuela de Ingeniería de Antioquia, Medellín (Colombia).

Luo, J., Boriboonsomsin, K., Barth, M., 2018. Reducing pedestrians’ inhalation of trafficrelated air pollution through route choices: Case study in California suburb. Journal of Transport \& Health, 10, 111-123.

Mannering, F.L., Shankar, V., Bhat, C.R., 2016. Unobserved heterogeneity and the statistical analysis of highway accident data. Analytic methods in accident research, 11, 1-16.

Mannering, F., 2018. Temporal instability and the analysis of highway accident data. Analytic methods in accident research, 17, 1-13.

Martins, L. D., Andrade, M. F., Freitas, E. D., Pretto, A., Gatti, L. V., Albuquerque, E. A., Tomaz, E., Guardani, M. L., Martins, M. H. R. B., Junior, O. M. A., 2006. Emission Factors for GasPowered Vehicles Traveling Through Road Tunnels in São Paulo, Brazil. Environmental Science \& Technology, 40(21), 6722-6729.

Mirasgedis, S., Hontou, V., Georgopoulou, E., Sarafidis, Y., Gakis, N., Lalas, D. P., Loukatos, A., Gargoulas, N., Mentzis, A., Economidis, D., Triantafilopoulos, T., Korizi, K., Mavrotas, G., 2008. Environmental damage costs from airborne pollution of industrial activities in the greater Athens, Greece area and the resulting benefits from the introduction of BAT. Environmental Impact Assessment Review, 28(1), 39-56.

MMA - Ministério do Meio Ambiente, 2011. $1^{\circ}$ Inventário Nacional de Emissões Atmosféricas por Veículos Automotores Rodoviários. Ministério do Meio Ambiente, Brasil.

MMA - Ministério do Meio Ambiente, 2014. $2^{\circ}$ Inventário nacional de emissões atmosféricas por veículos automotores rodoviários 2013. Ministério do Meio Ambiente, Brasil. Ano-Base 2012.

NZTA - New Zealand Transport Agency, 2013. Economic evaluation manual. Effective from 1 July. Republished 2016 (amendment 1). Effective from 1 July 2018. Disponível em: < https://www.nzta.govt.nz/assets/resources/economic-evaluation-manual/economic-evaluationmanual/docs/eem-manual.pdf $>$.

Ord, J. K., Getis, A., 1995. Local Spatial Autocorrelation Statistics: Distributional Issues and an Application. Geographical Analysis, 27(4), 286-306.

Pantangi, S.S., Fountas, G., Sarwar, M.T., Anastasopoulos, P.Ch., Blatt, A., Majka, K., Pierowicz, J, Mohan, S., 2019. The Development of New Insights into Driver Behavior to Improve High Visibility Highway Safety Enforcement (HVE) Programs, Analytic Methods in Accident Research, 21, 1-12. 
Pérez-Martínez, P.J., 2014. Emission factors of air pollutants from vehicles measured inside road tunnels in São Paulo: case study comparison. Int. J. Environ. Sci. Technol. 11, 2155-2168.

Pacheco, M.T., Parmigiani, M. M. M., Andrade, M. F., Morawska, L., Kumar, P., 2017. A review of emissions and concentrations of particulate matter in the three major metropolitan areas of Brazil. Journal of Transport \& Health, 4, 53-72.

Pan, L., Yao, E., Yang, Y., 2016. Impact analysis of traffic-related air pollution based on realtime traffic and basic meteorological information. Journal of Environmental Management 1-11.

Paoli, F., 2006. Simulação em túnel de vento da dispersão de uma pluma emitida por uma chaminé isolada. Dissertação (Mestrado). Universidade Federal do Rio Grande do Sul. Porto Alegre.

PMBC - Prefeitura Municipal de Balneário Camboriú, 1974. Lei n. 301/1974. Dispõe sobre o código de obras e edificações do município de Balneário Camboriú. Câmara Municipal de Balneário Camboriú.

PMBC - Prefeitura Municipal de Balneário Camboriú, 2017. Dados radares de trânsito, Consórcio FV. Unpublished raw data.

Rabl, A., Spadaro, J. V., 2000. Health Costs of Automobile Pollution. Revue Française d'Allergologie et d'Immunologie Clinique, 40(1), 55-59.

Rabl, A., Spadaro, J. V., Zwaan, B., 2005. Uncertainty of Air Pollution Cost Estimates: To What Extent Does It Matter? Environmental Science \& Technology, 39(2), 399-408.

Sánchez-Ccoyllo, O. R., Ynoue, R. Y., Martins, L. D., Astolfo, R., Miranda, R. M., Freitas, E. D., Borges, A. S., Fornaro, A., Freitas, H., Moreira, A., Andrade, M. F., 2008. Vehicular particulate matter emissions in road tunnels in Sao Paulo, Brazil. Environmental Monitoring and Assessment. 149(1-4), 241-249.

Shekarrizfard, M., Valois, M. F., Weichenthal, S., Goldberg, M. S., Shorshani, M. F., Cavellin, L. D., Croused, D., Parent, M. E., Hatzopoulou, M., 2018. Investigating the effects of multiple exposure measures to traffic-related air pollution on the risk of breast and prostate cancer. Journal of Transport \& Health, 11, 34-46.

Shindell, D. T., 2015. The social cost of atmospheric release. Climatic Change. 130:313-326.

Sibson, R. A., 1981. Brief Description of Natural Neighbor Interpolation. In: Interpolating Multivariate Data. New York: John Wiley \& Sons, 21-36.

Smit, R., Dia, H., Morawska, L., 2009. Road traffic emission and fuel consumption modelling: trends, new developments and future challenges. In: Traffic Related Air Pollution and Internal Combustion Engines. Nova Publishers.

Sun, Y., Moshfeghi, Y., Liu, Z., 2017. Exploiting crowdsourced geographic information and GIS for assessment of air pollution exposure during active travel. Journal of Transport \& Health, (6) 93-104

Tang, R., Ma, K., Zhang, Y., Mao, Q., 2013. The spatial characteristics and pollution levels of metals in urban street dust of Beijing, China. Applied Geochemistry, 35, 88-98.

Tischer, V., 2017. Homogeneous zones for urban mobility planning: case study of Balneário Camboriú, Brazil. Management Research and Practice. v.9, issue 3.

Tripathi, A., Souprayen, C., Stanley, A., Warrilow, N., 2018. Computational Fluid Dynamics or Gaussian - is there a right way to model gas dispersion? Risk Management Consultants UK. Fluidyn France Sarl. Available in: https://cdn.ima.org.uk/wp/wpcontent/uploads/2018/06/Tripathi4609.pdf. Acess: 21/09/2018. 
UK Governament, 2015. Air quality: economic analysis. Department for Environment, Food \& Rural Affairs. Available in: https://www.gov.uk/guidance/air-quality-economic-analysis\#damagecosts-approach.

USEPA - U.S. Environmental Protection Agency, 1995. AP 42, Fifth Edition Compilation of 894 Air Pollutant Emissions Factors, Volume 1: Stationary Point and Area Sources.

USEPA - Environmental Protection Agency, 2018. Air Quality Models. Support Center for Regulatory Atmospheric Modeling (SCRAM). Disponível em: $<$ http://www.epa.gov/scram001/aqmindex.htm >. Acess in: 15/12/2018.

VTPI - Victoria Transport Policy Institute, 2018. Transportation Cost and Benefit Analysis II - Air Pollution Costs. Victoria Transport Policy Institute. Acess in 02/01/2019.

Washington, S.P., Karlaftis, M.G., Mannering, F., 2011. Statistical and econometric methods 900 for transportation data analysis. Chapman and Hall/CRC.

WHO - World Health Organization, 2018. Air pollution. Health and sustainable development. Available in: < https:/www.who.int/sustainable-development/transport/health-risks/airpollution/en/>Acess in 19/12/2018.

Yao, E., Song, Y., 2013. Study on Eco-Route Planning Algorithm and Environmental Impact 906 Assessment. Journal of Intelligent Transportation Systems: Technology, Planning, and Operations, $17: 1,42-53$.

Zhang, S., Wu, Y., Huang, R., Wang, J., Yan, H., Zheng, Y., Hao, J., 2016. High-resolution 909 simulation of link-level vehicle emissions and concentrations for air pollutants in a traffic-populated eastern Asian city. Atmos. Chem. Phys., 16, 9965-9981.

Zou, B., Peng, F., Wan, N., Mamady, K., Wilson, G. J., 2014. Spatial Cluster Detection of Air 